\title{
MEASUREMENT PRACTICES FOR RELIABILITY AND POWER QUALITY
}

\section{A TOOLKIT OF RELIABILITY MEASUREMENT PRACTICES}

June 2004

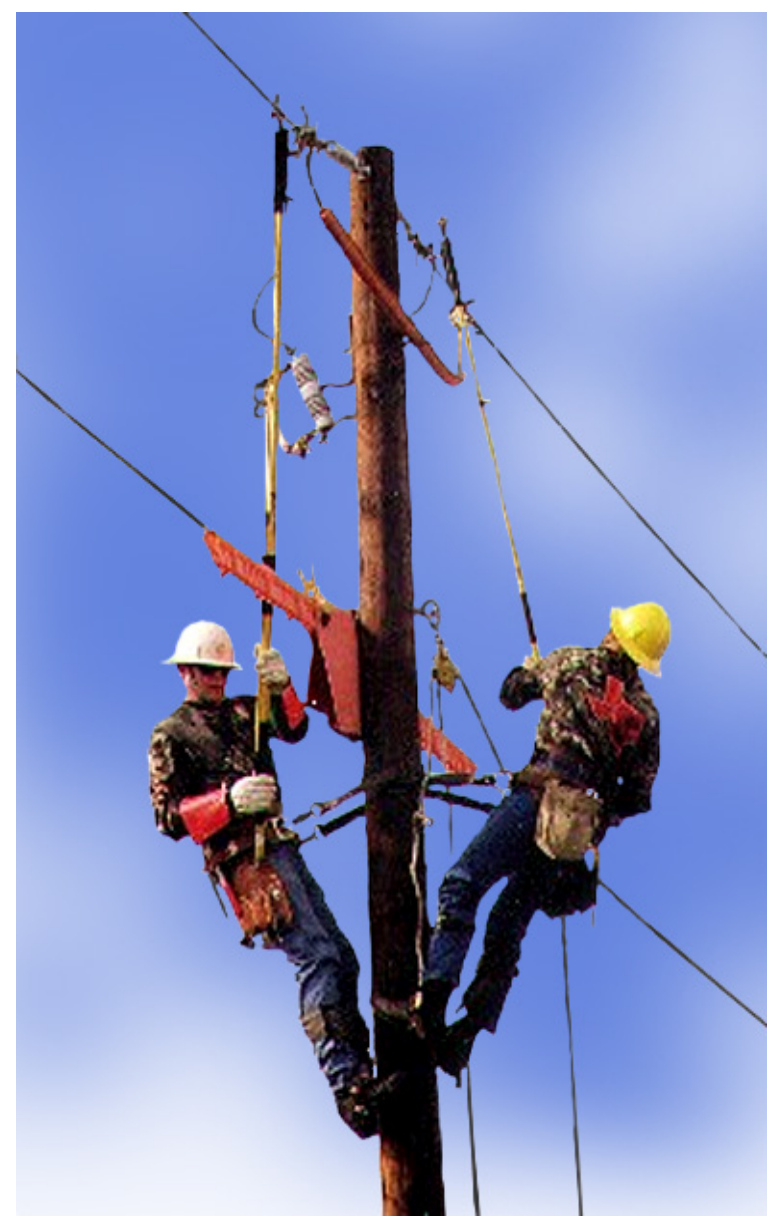



ORNL/TM-2004/91

\title{
MEASUREMENT PRACTICES FOR RELIABILITY AND POWER QUALITY
}

\section{A TOOLKIT OF RELIABILITY MEASUREMENT PRACTICES}

\author{
John D. Kueck and Brendan J. Kirby \\ Oak Ridge National Laboratory \\ Philip N. Overholt \\ U.S. Department of Energy \\ Lawrence C. Markel \\ Sentech, Inc.
}

June 2004

Prepared by

Oak Ridge National Laboratory

Oak Ridge, Tennessee 37831-6285

managed by

UT-BATTELLE, LLC

for the

U.S. Department of Energy

under contract DE-AC05-00OR22725 



\section{Contents}

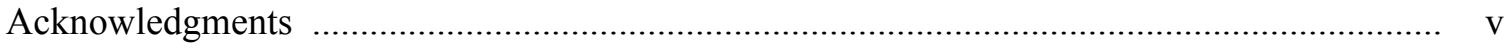

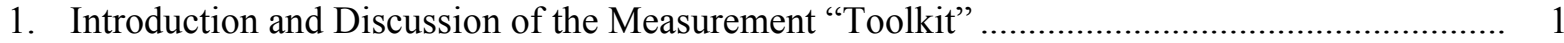

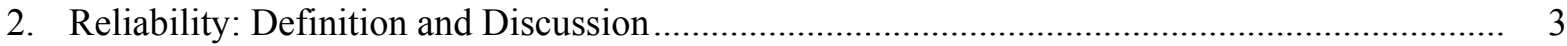

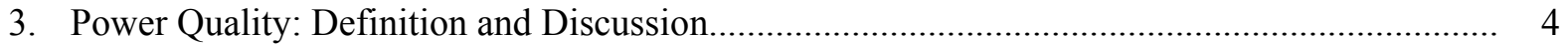

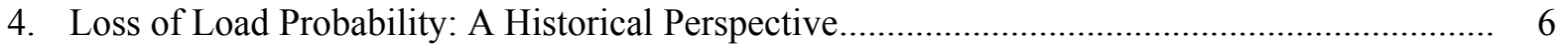

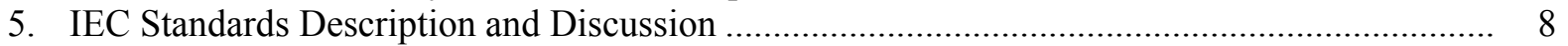

6. Pitfalls in Methods for Reliability Index Calculation ............................................................ 9

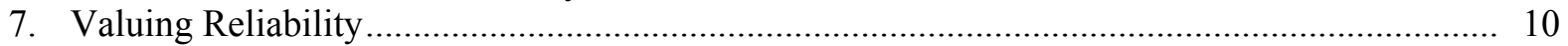

8. Standardizing Reliability and Power Quality Metrics .......................................................... 14

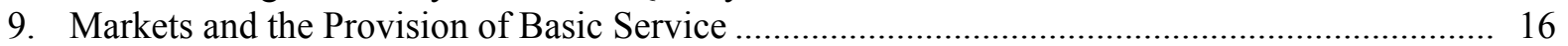

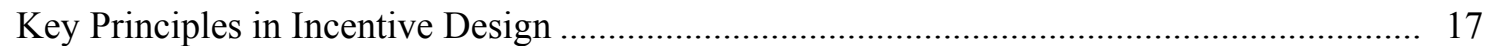

Markets Serving Individual Customers' Power Quality and Reliability Needs ..................... 17

Some Customers Want Lower-Quality Service.................................................................... 18

Transmission and Distribution Companies Providing Premium Power ................................. 18

Ensuring That Market Forces Work to Provide Power Quality and Reliability ...................... 20

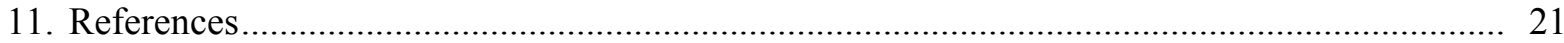

Appendixes

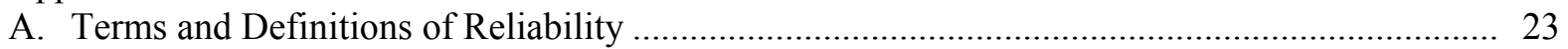

B. Power Quality Standards, Guidelines, and Measurement ..................................................... 27

C. Activities and Organizations Developing and Sharing Information

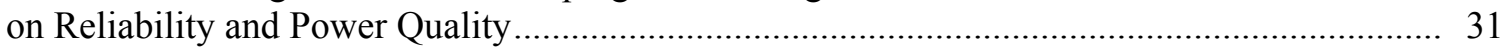

D. Summary Table: Power Quality Standards Development Activities ...................................... 37

E. Discussion of the Quality-Reliability-Availability Approach ................................................. 41

F. Industry Initiatives to Define Power Quality: Discussion of the SEMI, CBEMA and ITIC Curves 



\section{Acknowledgments}

The authors wish to thank Thomas Key and Arshad Mansoor of EPRI-PEAC, Georg Shultz of Rural Utilities Service, Mike Hyland of the American Public Power Association, Steven Lindenberg and Robert Saint of NRECA, Bernard Ziemaniek of EPRI, and Diane Barney of the NARUC Subcommittee on Electric Reliability Review for their kind contributions and review of this document. 



\section{Introduction and Discussion of the Measurement "Toolkit"}

This report provides a distribution reliability measurement "toolkit" that is intended to be an asset to regulators, utilities and power users. The metrics and standards discussed range from simple reliability, to power quality, to the new blend of reliability and power quality analysis that is now developing. This report was sponsored by the Office of Electric Transmission and Distribution, U.S. Department of Energy (DOE).

Inconsistencies presently exist in commonly agreed-upon practices for measuring the reliability of the distribution systems. However, efforts are being made by a number of organizations to develop solutions. In addition, there is growing interest in methods or standards for measuring power quality, and in defining power quality levels that are acceptable to various industries or user groups. The problems and solutions vary widely among geographic areas and among large investor-owned utilities, rural cooperatives, and municipal utilities; but there is still a great degree of commonality. Industry organizations such as the National Rural Electric Cooperative Association (NRECA), the Electric Power Research Institute (EPRI), the American Public Power Association (APPA), and the Institute of Electrical and Electronics Engineers (IEEE) have made tremendous strides in preparing self-assessment templates, optimization guides, diagnostic techniques, and better definitions of reliability and power quality measures. In addition, public utility commissions have developed codes and methods for assessing performance that consider local needs. There is considerable overlap among these various organizations, and we see real opportunity and value in sharing these methods, guides, and standards in this report.

This report provides a "toolkit" containing synopses of noteworthy reliability measurement practices. The toolkit has been developed to address the interests of three groups: electric power users, utilities, and regulators. The report will also serve to support activities to develop and share information

This report provides a measurement "toolkit" to address the interests of electricity users, utilities, and regulators. among industry and regulatory participants about critical resources and practices.

The toolkit has been developed by investigating the status of indices and definitions, surveying utility organizations on information sharing, and preparing summaries of reliability standards and monitoring requirements - the issues, needs, work under way, existing standards, practices and guidelines-for the following three classifications:

- terms and definitions of reliability;

- power quality standards, guidelines, and measurements;

- activities and organizations developing and sharing information on distribution reliability.

As these synopses of reliability measurement practices are provided, it must be noted that an economic penalty may be associated with requiring too high a reliability level from the distribution system for all customers. It may be appropriate for the distribution system to supply only some base, generally accepted level of reliability. This base level would be adequate for the majority of customers. Users who need a higher level may find it economical to supply using distributed energy resources (DER) and other local solutions to reliability and power quality needs. Local solutions implemented by the customer may be the most cost-effective method for addressing the more stringent needs of a digital economy. These local solutions include energy storage, small distributed generators, and microgrids.

This report also considers the market's role in addressing reliability issues and requirements. The customer's needs are discussed in view of issues such as power quality requirements of digital electronic equipment, the cost of outages, the cost of storage and new infrastructure, and natural gas 
prices. The market role in addressing these issues and requirements is explored. The economic considerations associated with the reliability issues are discussed, as well as the levels at which these economic decisions could be made. Finally, a discussion is provided of the role DER could play in addressing reliability needs, and the possible role of the market in providing needed levels of reliability.

The toolkit is provided in a set of appendices. These appendices are summarized as follows:

A. Terms and Definitions of Reliability — a listing and synopsis of the major standards and codes for reliability

B. Power Quality Standards, Guidelines, and Measurements - a listing and synopsis of the significant standards for power quality

C. Activities and Organizations Developing and Sharing Information on Reliability and Power Quality - a list of organizations having a significant ongoing activity in power quality and reliability

D. Summary Table: Power Quality Development Activities - a succinct table which provides the power quality topic, the standards body, the project identification, and the title of the document

E. Discussion of the Quality-Reliability-Availability Approach — an EPRI initiative that takes an integrated look at power quality, reliability, end user needs, and the service contract

F. Industry Initiatives to Define Power Quality (SEMI, CBEMA, ITIC) - a summary of specific acceptable levels of power quality established by three industry organizations. 


\section{Reliability: Definition and Discussion}

In brief, reliability has to do with total electric interruptions - complete loss of voltage, not just deformations of the electric sine wave. Reliability does not cover sags, swells, impulses or harmonics. Reliability indices typically consider such aspects as

- the number of customers;

- the connected load;

- the duration of the interruption measured in seconds, minutes, hours, or days;

- the amount of power (kVA) interrupted; and

- the frequency of interruptions.

Power reliability can be defined as the degree to which the performance of the elements in a bulk system results in electricity being delivered to customers within accepted standards and in the amount desired. The degree of reliability may be measured by the frequency, duration, and magnitude of adverse effects on the electric supply. ${ }^{1}$.

There are many indices for measuring reliability. The three most common are referred to as SAIFI, SAIDI, and CAIDI, defined in IEEE Standard 1366 (see Appendix A).

- SAIFI, or system average interruption frequency index, is the average frequency of sustained interruptions per customer over a predefined area. It is the total number of customer interruptions divided by the total number of customers served.

- SAIDI, or system average interruption duration index, is commonly referred to as customer minutes of interruption or customer hours, and is designed to provide information as to the average time the customers are interrupted. It is the sum of the restoration time for each interruption event times the number of interrupted customers for each interruption event divided by the total number of customers.

- CAIDI, or customer average interruption duration index, is the average time needed to restore service to the average customer per sustained interruption. It is the sum of customer interruption durations divided by the total number of customer interruptions.

A reliability index that considers momentary interruptions is MAIFI, or momentary average interruption frequency index.

- MAIFI is the total number of customer momentary interruptions divided by the total number of customers served. Momentary interruptions are defined in IEEE Std. 1366 as those that result from each single operation of an interrupting device such as a recloser.

The major drawback to reliability metrics is that there is a great deal of debate about comparing these indices from one geographic area to another and exactly how the input data is to be applied in making the calculations. This is discussed further in Chapter 6, "Pitfalls in Methods for Reliability Index Calculation." In addition, there are concerns about how to "normalize" the indices for adverse weather. Many state public utility commissions require utilities to compute and track certain reliability indices, but comparing them from region to region and utility to utility has been problematic due to differences in how the data is applied, system designs, weather differences, and even differences in vegetation growth. Because of this, the indices are limited in their usefulness. If the calculation method is kept the same, they are useful within a specific geographic area in evaluating changes in reliability over time, perhaps as a measurement of the effectiveness of maintenance practices. 


\section{Power Quality: Definition and Discussion}

The IEEE Standard Dictionary of Electrical and Electronics Terms defines power quality as "the concept of powering and grounding sensitive electronic equipment in a manner that is suitable to the operation of that equipment." Power quality may also be defined as "the measure, analysis, and improvement of bus voltage, usually a load bus voltage, to maintain that voltage to be a sinusoid at rated voltage and frequency." 2

Today's electronic loads are susceptible to transients, sags, swells, harmonics, momentary interruptions, and other disturbances that historically were not cause for concern. For sensitive loads, the quality of electric service has become as important as its reliability. Power quality is a new phenomenon. Events such as voltage sags, impulses, harmonics, and phase imbalance are now power quality concerns. Power quality problems have a huge economic impact. As a result, any discussion of power system reliability must also include power quality.

The body of literature on reliability indices and calculation techniques represents a fairly mature discipline. In contrast, power quality references are works in progress, often revised and frequently outdated. There are several reasons for this:

- Reliability and availability describe clearly defined events-loss of power. Power quality incidents are often momentary - a fraction of a cycle - and hard to observe or diagnose. Power quality measurement devices had to be developed so that the phenomena could be observed before power quality could be analyzed.

- The growing digital load, and the increased sensitivity of some of these loads, means that the definition of a power quality incident keeps changing. Ten years ago, a voltage sag might be classified as a drop by $40 \%$ or more for 60 cycles, but now it may be a drop by $15 \%$ for 5 cycles.

- The constituencies concerned with power quality are very diverse-utilities, regulators, facilities managers, equipment manufacturers, electrical engineers, electrical inspectors, building designers, electricians. All these groups have different definitions, objectives, responsibilities, criteria, and levels of sophistication in measurement and modeling capabilities.

- Power quality often involves safety issues (e.g., grounding and elevated neutral voltages) that were not ever a part of reliability assessment.

- Power quality involves design issues, such as the stiffness of the user's distribution system, that did not have such an impact on operational reliability before.

- Power quality problems can easily cause losses in the billions of dollars, and an entire new industry has recently grown up to diagnose and correct these problems.

- Often, power quality problems can best be addressed with local corrective actions, and these local devices are undergoing a revolution themselves, with changes occurring rapidly.

There are many measures and indices of power quality. Some of the more common indices are the following:

- Total harmonic distortion (THD): The ratio of the RMS value of the sum of the individual harmonic amplitudes to the RMS value of the fundamental frequency

- $\mathrm{K}$ factor: The sum of the squares of the products of the individual harmonic currents and their harmonic orders divided by the sum of the squares of the individual harmonic currents

- Crest factor: The ratio of a waveform's peak or crest to its RMS voltage or current

- Flicker: A perceptible change in electric light source intensity due to a fluctuation of input voltage. It is defined as the change in voltage divided by the average voltage expressed as a percent. This ratio is plotted vs the number of changes per minute to develop a "flicker curve." 
There are many more indices and definitions of power quality. A list of power quality standards is provided in Appendix B. The definitions are rapidly changing, and often quite specialized in their application. For example, there is a harmonic voltage factor for motor application that is similar to, but not the same as, THD. The motor harmonic voltage factor is defined in NEMA Standard MG-1, a standard for motors and generators.

Typically, electrical engineers who work in various fields of electrical engineering - power systems, communications, computers - are familiar with the indices and definitions that pertain to their particular disciplines. There is also a new group of consultants who deal exclusively with power quality problems. Some industries are also developing their own standards for power quality; these are discussed further in Appendix F.

Some power quality problems are supplied to customers' load through the utility distribution system, and some are caused by the customers themselves. Many problems originate with one customer and travel through the distribution system, and even the transmission system, to impact other customers. Some manufacturers are now equipping their products with filters and short-term storage devices so that they will be immune to many power quality problems. Local solutions to power quality problems tend to be the most cost-effective.

Knowing what power quality to expect from the power supplier is critical to designing power quality tolerance in end-use equipment, thus benefiting the customer, the utility, and the equipment manufacturer. 


\section{Loss of Load Probability: A Historical Perspective}

Twenty years ago, when a distribution feeder recloser caused a momentary interruption to clear a fault, this was counted as a reliability improvement, since the barely noticeable flicker prevented an extended outage. Ten years ago, the recloser operation was regarded as an outage, as it interrupted electronic clocks, VCRs, personal computers (PCs), etc. Now, as appliances come equipped with "ride-through" capacitors and more PCs are using uninterruptible power supplies, the recloser operation may soon be classified again as a non-outage. For the reliability of 21 st-century power systems, this development has two implications:

- It may not be appropriate to require the utility alone to meet reliability and power quality criteria; the customer, too, must take some responsibility.

- The "reliability" of electric service is a function of the loads served, as well as of the characteristics of the electricity provided.

Consider the historical use of loss-of-load probability (LOLP), which has been used for years as the single most important metric for assessing overall reliability. LOLP is a projected value of how much time, in the long run, the load on a power system is expected to be greater than the capacity of the generating resources. It is calculated using probabilistic techniques. In setting an LOLP criterion, the rationale is that a system strong enough to have a low LOLP can probably withstand most foreseeable outages, contingencies, and peak loads. A utility is expected to arrange for resourcesgeneration, purchases, load management, etc. - so the resulting system LOLP will be at or below an acceptable level.

LOLP is really not a probability but an expected value. ${ }^{3}$ It is sometimes calculated on the basis of the peak hourly load of each day, and sometimes on each hour's load (24 in a day). As a result, the same system may be characterized by two or more values of LOLP,

Loss-of-load probability characterizes the adequacy of generation to serve the load on the system. It does not model the reliability of the transmission and distribution system where most outages occur. depending upon how LOLP is calculated. Moreover, LOLP is used to characterize the adequacy of generation to serve the load on the bulk power system; it does not model the reliability of the power delivery system - transmission and distribution-where the majority of outages actually occur.

The LOLP criterion is much like a rule of thumb to maintain a $25 \%$ reserve margin, but it is an improvement because it takes into account system characteristics such as generator reliability, load volatility, correlation of summer peak loads, and unit deratings. Thus, where one utility might function acceptably with a $25 \%$ reserve margin, another might survive with $20 \%$, and still another might require $30 \%$ to maintain the same LOLP. If utilities were planned so that they maintain an appropriate reserve margin, different utilities should have different reserve margins because the same reserve margin in different utilities would result in different levels of reliability.

The common practice was to plan the power system to achieve an LOLP of 0.1 days per year or less, which was usually described as "one day in ten years." This description resulted from erroneously assuming the LOLP was a probability rather than an expected value, interpreting the 0.1 criterion as a probability of 0.1 per year that load would exceed supply, and simplifying this as "a probability of 0.1 per year results in an interruption every 10 years." In addition to the definition error, there are several problems with this use of LOLP:

- LOLP alone does not specify the magnitude or duration of the electricity shortage. As an expected value, it does not differentiate between one large shortfall and several small, brief ones. 
- Different LOLP calculation techniques can result in different indices for the same system. Some utilities calculate LOLP based on the hour of each day's peak load (i.e., 365 computations), while others model every hour's load (i.e., 8760 computations).

- In fact, "one day in ten years" is not acceptable. The Northeast blackouts of 1965 and 2003 and the New York City blackout of 1977 resulted in major changes to power system planning and operating procedures to try to prevent their recurrence, even though they occurred more than ten years apart.

- LOLP does not include additional emergency support that one control area or region may receive from another, or other emergency measures that control area operators can take to maintain system reliability.

- Major loss-of-load incidents usually occur as a result of contingencies not modeled by the traditional LOLP calculation. Often, a major bulk power outage event is precipitated by a series of incidents, not necessarily occurring at the time of system peak (when the calculated risk is greatest).

All of these problems stem from a further misunderstanding of the meaning of reliability indices, such as LOLP or frequency and duration. LOLP is an index, a surrogate indicator of the robustness of the bulk power system. The vertically structured utility will build generation or enter into power purchase contracts to achieve the required LOLP, but LOLP is not necessarily an accurate predictor of the resulting incidence of electricity shortages.

In the vertically structured utility industry, typical guidelines for prudent planning were

- $\quad$ LOLP of 0.1 or less and

- ability to withstand the single maximum credible multiple contingency (or the worst two or three) at the time of heaviest load.

These were accepted as best practices of that time; however, there was criticism that utilities were "gold-plating" their systems by building too much capacity. The feeling was that the level of reserves or redundancy provided by the utilities was not cost-justified compared with the costs of outages. Generation reserves were declining under declining regulation. In the restructured utility environment they are now greatly increased in many regions. Transmission reserves, which are regulated, are still declining. 


\section{IEC Standards Description and Discussion}

The International Electrotechnical Commission (IEC) (www.iec.ch) is an organization based on a structure of national committees that appoint experts to IEC working groups to develop standards and other documents (e.g., recommended practices, guidelines). There are about 100 such working groups. The working group documents are reviewed and approved by the participating national committees on a one-country, one-vote basis.

Among the documents issued by IEC working groups are international standards, technical specifications, technical reports, and industry technical agreements. International standards issued by IEC are publications resulting from international consensus or approval. IEC technical specifications are similar to standards but have not yet obtained the required consensus, or they cover practices which the working group feels are premature to standardize. IEC technical reports contain data from surveys or delineate the "state of the art" in a technical area. The IEC has also adopted a procedure for industry technical agreements (ITAs), which are platforms for reaching technical agreements among key industry organizations in time-critical market sectors. ITAs are intended to be used by industry in high-tech areas where international consensus standards are not needed immediately. IEC technical committees developing power quality-related standards are

- SC37A-Low-voltage surge protective devices

- SC77A-EMC-Low-frequency phenomena

- TC64-Electrical installations

- TC81-Lightning protection

The IEC's strength is that its standards result from multinational input and are the result of international consensus. However, IEC standards are often different from, and sometimes incompatible with, U.S. standards developed by ANSI, IEEE, the National Fire Protection Association, or other U.S. code-making bodies. Table 1 shows the correspondence between IEC and some other power quality standards.

Table 1. Correspondence Between IEEE, ANSI, and IEC power quality standards

\begin{tabular}{lll}
\hline Disturbance & IEEE & IEC \\
\hline Harmonic environment & None & IEC 1000-2-1/2 \\
Compatibility limits & IEEE 519 & IEC 1000-3-2/4 (555) \\
Harmonic measurement & None & IEC-1000-4-7/13/15 \\
Harmonic practices & IEEE 519A & IEC-1000-5-5 \\
Component heating & ANSI/IEEE C57.110 & IEC 1000-3-6 \\
Under-sag-environment & IEEE 1250 & IEC 38, 1000-2-4 \\
Compatibility limits & IEEE P1346 & IEC 1000-3-3/5 (555) \\
Sag measurement & None & IEC 1000-4-1/11 \\
Sag mitigation & IEEE 446, 1100, 1159 & IEC 1000-5-X \\
Fuse blowing/upsets & ANSI C84.1 & IEC 1000-2-5 \\
Oversurge environment & ANSI/IEEE C62.41 & IEC 1000-3-7 \\
Compatibility levels & None & IEC 3000-3-X \\
Surge measurement & ANSI/IEEE C62.45 & IEC 1000-4-1/2/4/5/12 \\
Surge protection & C62 series, 1100 & IEC 1000-5-X \\
Insulation breakdown & By product & IEC 664 \\
\hline
\end{tabular}

Source: EPRI-Power Electronics Application Center 


\section{Pitfalls in Methods for Reliability Index Calculation}

Because some utilities are adopting performance-based rates, the importance of calculating reliability indices is growing. In order to do an "apples-to-apples" comparison between utilities, it is essential that reliability index calculation and reporting methods be uniform. A nationwide survey of information used for calculating distribution reliability indices was recently performed. ${ }^{4}$. The survey found a number of different sources of disparity between utility practices. Some of the most significant issues are summarized as follows.

One significant source of discrepancies is step restoration. When a utility takes actions to restore power after a large-scale outage, the restoration proceeds in steps. If customer minutes are not tracked accurately as these steps are taken, the "start" and "end" times of the interruption can increase or decrease and have a major impact on the calculated indices.

How far down does the utility go in analyzing an interruption? Does the analysis go to the distribution substation, circuit breaker, recloser, sectionalizer, fuse, transformer, service, or meter? Survey results have shown that the system average interruption duration index (SAIDI) can double with the inclusion of data down to the fuse level. Some utilities calculate SAIDI only down to the substation level.

The momentary average interruption frequency index (MAIFI), which is the total number of customer momentary interruption events divided by the total number of customers served, measures data on "momentary" interruptions that result in a zero voltage. For example, two circuit breaker open operations equals two momentary interruptions. Another index, the system average interruption frequency index (SAIFI), is the total number of customer interruptions divided by the total number of customers served. Some utilities include MAIFI data in the SAIFI calculation. When MAIFI data is included in the SAIFI calculations, the SAIFI index can triple. In addition, obtaining the momentary information accurately is sometimes quite difficult because some reclosers and distribution breakers are not equipped with SCADA.

A "major event" is defined in IEEE Standard 1366 as a catastrophic event that exceeds the design limits of the power system. Utilities are permitted to exclude major events when calculating their indices. There is a wide variance, however, in how a major event is defined in practice and how it is used for excluding abnormal data. Some utilities use a major event definition that is set by the governing regulatory agency; others use their own definition. This has a tremendous impact on the calculated indices. Of the surveyed utilities, $70 \%$ said that they had a major event definition, and 53\% said that their major event definition was the same as that used by the governing regulatory agency.

Finally, how data are entered has a bearing on validity. Some utilities have a computer-based system for calculating indices in which interruption data are automatically entered, while others enter data manually through a spreadsheet-based system. It was found that the more sophisticated the computerized system is, the more likely it is that the data will be consistent and reflect actual system performance.

In addition, there was a feeling expressed among the survey respondents that generation and transmission should have their own reliability indices, and that these should not be included in the calculation of distribution reliability. One utility found that including transmission and generation interruptions increases SAIDI by $131 \%$ and SAIFI by $120 \%$.

It is clear that the process used for calculating reliability indices can vary greatly from utility to utility. The input data sources vary tremendously, and there are major differences in basic calculation methods. The indices are essentially useless for comparing utility performance unless these discrepancies are identified and understood. When applied consistently, the indices are useful for examining year-to-year trends within a specific utility, but when comparing utilities with different data collection methods and definitions, as described above, the indices presently can be quite misleading. 


\section{Valuing Reliability}

Although reliability metrics do have their shortcomings, as discussed in Section 6, they are useful for trending when applied consistently with an unchanging set of calculation procedures. For example, Pacific Power has developed several performance standards that are on file with the applicable state commissions. Failure to meet these standards results in financial penalties for the utility. Four of these standards are as follows:

1. In each state, annual SAIDI will be improved by $10 \%$ between 2003 and 2005 .

2. In each state, annual SAIFI will be improved by $10 \%$ between 2003 and 2005 .

3. In each state, annual MAIFI will be improved by 5\% between 2003 and 2005 .

4. In each state, the five worst-performing distribution circuits will be improved by $20 \%$ over a 2 -year period. Five new circuits will be selected in each state each year for a 5-year period.

In addition to these metrics, which are part of the agreement with the public utility commissions, Pacific Power also has customer guarantees, again tied to financial penalties if the utility fails to deliver. Three of these are summarized as follows: ${ }^{5}$

1. After an interruption, power will be restored within 24 hours, barring damage due to extreme weather. If this condition is not met, the residential customer receives $\$ 50$, and the commercial customer, $\$ 100$.

2. Power will be switched on within 24 hours of the customer's request or the customer receives $\$ 50$.

3. Customers will be notified two days prior to a planned interruption; if not, each customer receives $\$ 50$.

These standards of reliability are part of a program to establish a high level of customer service as part of a fundamental business philosophy. The guarantees provide a concrete example of the value of reliability.

The worst-performing distribution circuits are chosen for upgrade by Pacific Power using the customer hours interrupted, or the numerator of SAIDI. ${ }^{6}$ Experienced judgment can then be used to implement known improvements based on reliable rules of thumb and without extensive analysis.

On the other hand, some utilities such as Commonwealth Edison in Chicago are using largescale reliability modeling to analyze circuits and choose optimal improvements based on cost and benefit.

After a series of major distribution outages in Commonwealth Edison territory in 1999, ComEd launched a comprehensive investigation looking at equipment, design, personnel, and operations. The corrective actions included substation and feeder inspections, installation of new feeders, feeder upgrades, substation expansions, building of new substations, and the implementation of a new maintenance program. ComEd also developed a predictive reliability model consisting of more than 3,300 feeders. The model provided an intelligent system to automatically identify potential reliability problems and to recommend reliability improvement projects based on expected benefits and costs. ${ }^{7}$ A reliability assessment model quantifies reliability characteristics based on system topology and component reliability data. The model identifies areas of inherently good or poor reliability, and also identifies overloaded and undersized equipment that degrade system reliability. Some typical improvements that a predictive reliability model can explore include

- load transfers between feeders,

- building of new substations and substation expansions,

- addition of line reclosers, 
- sectionalizing switches,

- adding new feeder tie points,

- automating feeders,

- undergrounding of circuits, and

- replacement of aging equipment.

The ComEd model uses a simulation that assesses each contingency, determines the impact, and weights the impact by the contingency's probability of occurrence. A sample reliability assessment is shown in Figure 1. Areas with relatively low reliability are shaded in red. Potential problem areas can be quickly identified. If a red area is adjacent to a blue area, it may be desirable to transfer some customers through reconfiguration to improve the reliability of the transferred customers and to help equalize the reliability of the two areas.

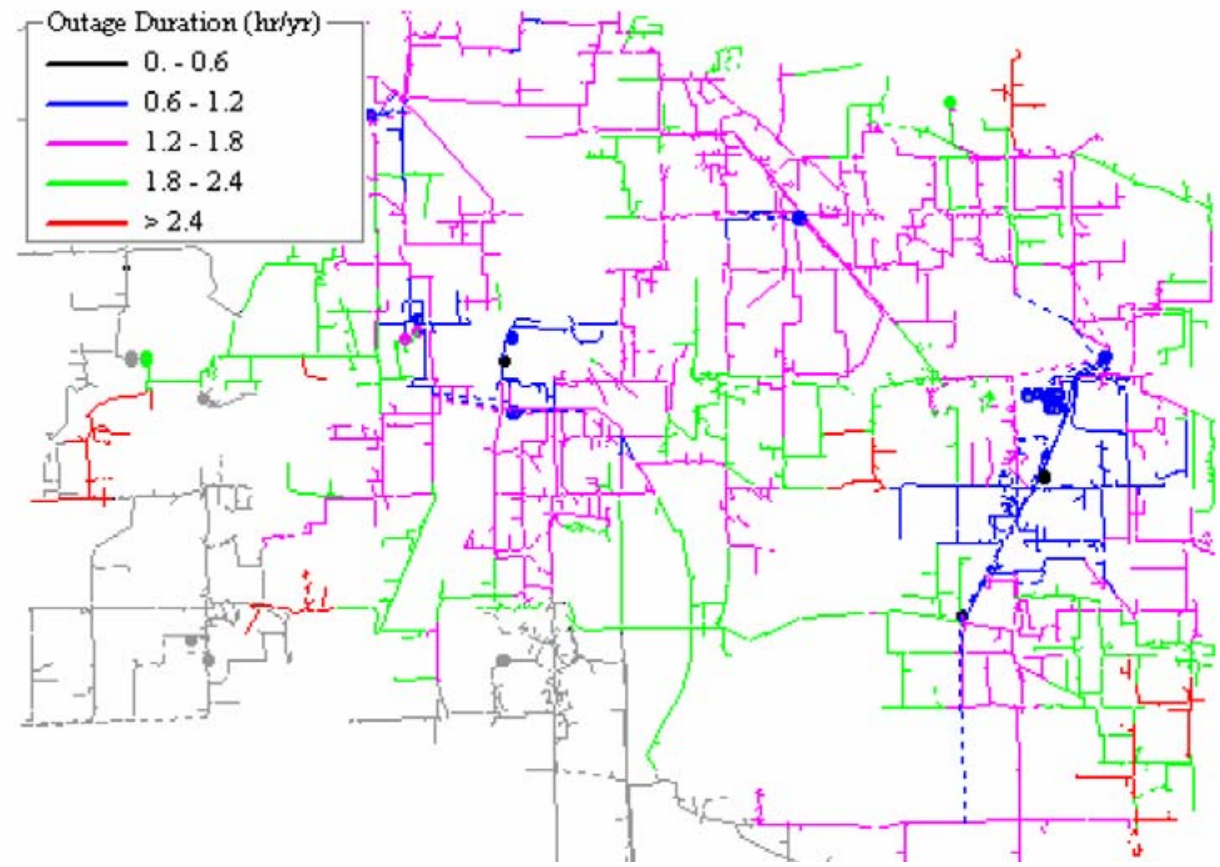

Figure 1. Reliability assessment results. Components are shaded based on expected annual outage hours, a primary driver of SAIDI. Source: Ref. 7.

Computer-generated reliability improvements can be evaluated and different approaches can be compared from a cost-benefit perspective. Interestingly, the cost-effectiveness of reliability improvement projects varies widely from area to area. After the reliability model was completed, an intelligent system was used to automatically identify potential reliability problems and recommend reliability improvement projects based on benefits and costs. Figure 2 shows that the highest ranked project for the Northeast region is more than three times as cost-effective as the highest ranked project in the Southern region. The cost benefit varies widely, different types of projects tend to be more effective for different regions, and the best allocation of money will require flexibility in both the types of projects that are funded and the level of funding for each geographic region. This graph shows that the most cost-effective reliability gains can be made in the Northeast. 


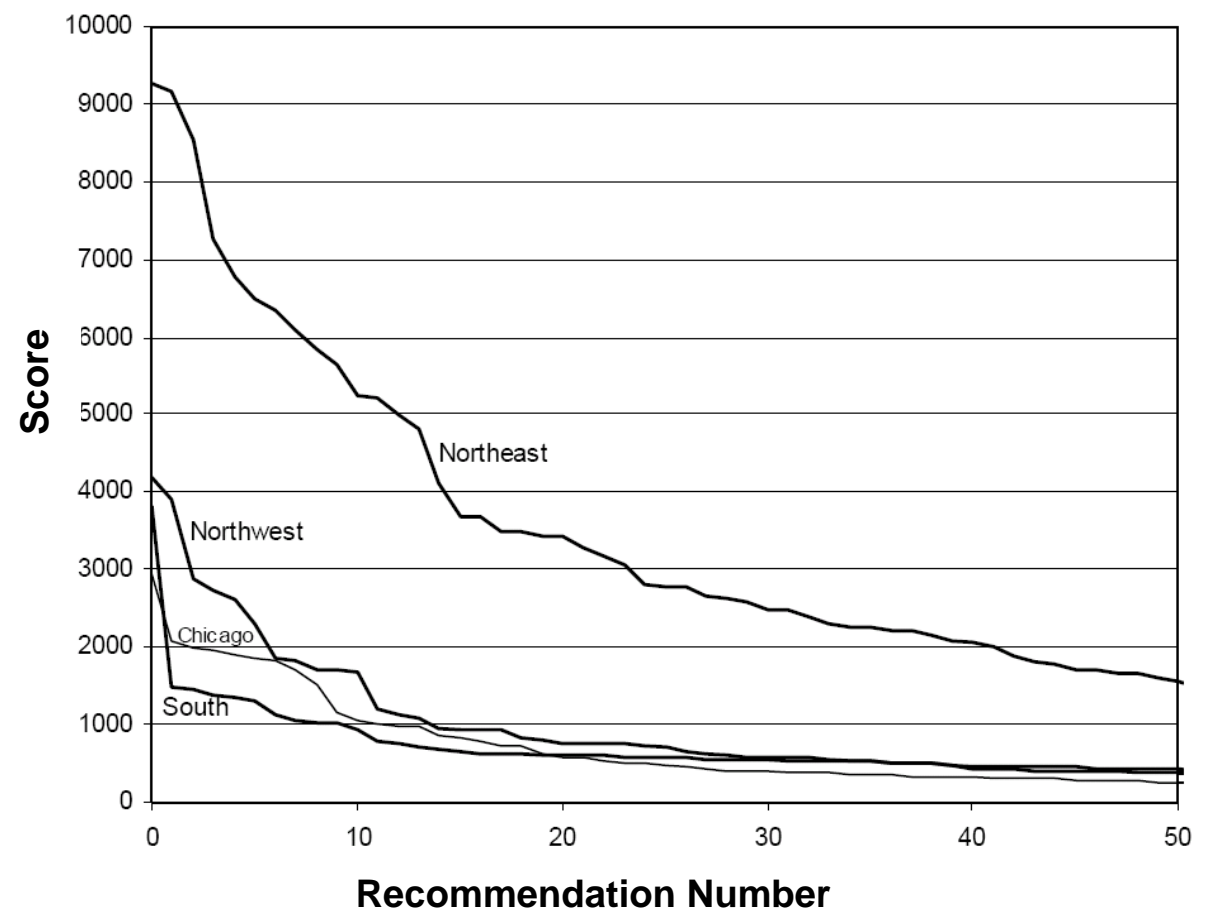

Figure 2. Plot of recommendations vs reliability score. Source: Ref. 7.

Some of the recommendations for reliability improvement projects included the following:

- Transfer path upgrade: A transfer path is an alternate path to serve load after a fault occurs. If a transfer path is constrained due to small conductor sizes, reconductoring may be cost effective.

- New tie points: A tie point is a normally open switch that allows a feeder to be connected to an adjacent feeder. Adding new tie points increases the number of possible transfer paths.

- Increased line sectionalizing: Increased line sectionalizing is accomplished by placing normally closed switching devices on a feeder. Adding switches improves reliability by allowing more flexibility during post fault system reconfiguration.

- Feeder automation: Adding SCADA-controlled switches on feeders will allow automated postfault system reconfiguration.

The entire ComEd distribution modeling effort required less than one year. The results found that the most cost-effective approaches to improving reliability are not always obvious and can vary by feeder and region. ${ }^{7}$

Evaluating reliability improvements can thus require a range of techniques from detailed probability modeling of the entire system to using proven rules of thumb to plan upgrades. Interestingly, the utility discussed here that is simply using tried-and-true methods to plan improvements is meeting its reliability standards every year and posting the results on its website. 
Conversely, the utility that developed the comprehensive reliability analysis model and the intelligent system to automatically identify potential problems and recommend improvements, made the news with three major outages in one summer. The subsequent effort modeled, calibrated, and assessed the reliability of more than 3300 feeders. 


\section{Standardizing Reliability and Power Quality Metrics}

Utilities and/or distribution companies are able to provide only a level of reliability and power quality commensurate with the designs of their distribution systems. These levels vary greatly among locations and among distribution system designs. Underground network systems with several redundant primary feeders like those used in major metropolitan areas can provide very high levels of reliability and power quality, while rural distribution systems with long overhead radial feeders often experience voltage sags. In some cases, feeders for industrial plants come directly from transmission substations and have an inherently higher level of reliability and power quality.

These design features and arrangements are not possible in every location. Assumptions regarding the level of reliability and power quality should not be developed in a vacuum, without considering constraints on the local utility. A number of utility measures can be taken to minimize interruptions. IEEE Std 1250-1995 provides two sets of measures, design measures and operating measures:

\section{Design measures}

General circuit layout and construction Circuit exposure, length, and type

Protective coordination

Fault sectionalizing

Grounding considerations

Surge arrestor application

\section{Operating measures}

Equipment inspection and maintenance Line inspection and maintenance Right-of-way inspection and maintenance Prompt identification of chronic problems Analysis of interruption data Line monitoring

In the future, a level of required reliability and power quality may be developed and specified for a broad range of industrial processes. This has already been done for the computer industry and the semiconductor manufacturing industry. Levels could be developed for residences, commercial establishments such as restaurants, critical facilities such as hospitals and communication networking centers, and industry.

A reasonable expected level of reliability and power quality could be developed for specific distribution locations. As discussed earlier, these levels would be a function of a number of variables including climate, design, and maintenance. It would be essential to keep index calculation methods uniform. For example, the method for acquiring restoration times after an outage would have to be identical, both in theory and practice, between utilities. Step restoration, where end times of interruption are measured in large blocks (for example, at the substation level), can lead to large discrepancies if other utilities are measuring time at the sublateral or even customer level. Ideally, the actual individual customer restoration time would be measured and used in the index calculation.

Development of such standards would require a computer-based system that is programmed and managed identically among the utilities to acquire data and calculate indices. Definitions of concepts such as a major event would also have to clearly defined and practiced uniformly. If this could be done, this common method of computer-based data acquisition and calculation would produce indices that were meaningful for comparison between utilities.

A drawback to such a standardized programmed and managed reliability database is that some utilities will inherently have better reliability indices than others due to simple differences in climate and geography. For example, factors such as the number of lightning strikes, the length of exposed feeders, a desert climate, and urban network system designs will have a significant impact on the reliability figures, independent of the actions of the utility to competently operate and maintain its system. As noted in the previous section, Pacific Power is presently using performance incentives based on reliability indices. Once the calculation method is well defined and understood by both the 
utility and the regulator, it provides a common ground for assessing performance. In New York State, performance metrics are quite well defined and are agreed upon by both utilities and the public service commission. 


\section{Markets and the Provision of Basic Service}

The transmission and distribution (T\&D) system is inherently a communal asset. The system provides the same level of service to all customers, or to all customers within a given area. Unlike the system for supplying energy, the T\&D system does not easily differentiate among different customers' needs. Consequently, there must be a communal decision concerning the basic level of power quality and reliability the system will provide to all customers. This is inherently a regulatory decision that regulators make by considering the value of reliability and power quality to the aggregation of all customers and comparing that value with the cost of providing that level of service. Once the regulator decides on the level of power quality and reliability that is desired, market forces can be used to motivate the regulated distribution company to provide that service at the lowest cost. Performance-based rates can provide a financial incentive for the $T \& D$ company to deliver the desired level of power quality

The transmission and distribution system is a communal asset, providing the same level of service to all customers in a given area. So there must be a communal decision as to the basic level of power quality and reliability it will provide to all customers. and reliability.

There is generally a tradeoff between the price of the energy delivery service and quality/reliability. (There are some situations where price reductions and increases in service quality can be achieved simultaneously, but generally there is a tradeoff.) Incentives to the T\&D company to reduce the cost of energy delivery may encourage reductions in service quality. Hence, there is a clear need for performance targets and incentives to ensure that service quality is not sacrificed.

Once targets have been established that define the basic service for power quality and reliability, incentives can be established to motivate the T\&D utility to meet these targets. Annual adjustments can be made to the T\&D company's maximum allowable price (and consequently revenues) based on the service performance achieved relative to set targets. The payments should be set at or above the projected cost of improving power quality and reliability, as an incentive for the utility to meet the targets (the utility keeps any profit that results if the utility exceeds the targets at costs that are below projections). The payment should be at or below the value placed on the improvement by customers. There is no point in increasing performance if the cost exceeds the value.

Basing these payments on the annualized cost of improving power quality and reliability, rather than on the value to customers, also limits the distribution company's financial risk. This is especially important when an incentive program is first being established and the risks are not known precisely. Penalties and incentives should be symmetric. That is, the distribution company should lose revenue if it fails to meet the expected targets and should receive extra revenue if exceeds the expected targets.

It is also important to provide a mechanism such as compensation to individuals whose power quality and/or reliability is significantly below standard so the desired improvements in average performance do not mask problem spots. Improving reliability on one feeder is no use to customers on another feeder. We must be wary of averages.

In Victoria, Australia, where incentive rates are being tried, ${ }^{8}$ the threshold for requiring payments for poor performance was set at approximately four times the average duration of interruptions. The expected cost to the distribution companies is about $0.25 \%$ of revenue; the utility is running little risk. However, these incentives should encourage distributors to undertake capital expenditures to improve the quality and reliability of supply by introducing new technology as well as by making conventional investments.

The Victoria experience makes the statement that customers would much rather receive quality service than receive payment for poor reliability. The payments made to customers for unusually poor 
power quality or reliability performance are meant to motivate the utility; they are not intended to adequately compensate the customer for its loss.

\section{Key Principles in Incentive Design}

Several key principals for devising quality incentives are emerging in energy markets:

- Clearly specify the metrics and incentives in advance.

- Make the metrics and incentives as simple as possible for both distributors and customers without distorting the incentives.

- Ensure that performance measurement is verifiable.

- Address worst-case performance as well as average performance.

- Provide penalties for under-performance as well as incentives for exceeding targets.

- Limit the financial risk, especially when first implementing the system, but make the incentive large enough to provide real motivation. Incentives should be greater than the cost to the distributor to achieve the incremental improvement, but less than the value to customers.

Interestingly, Victoria includes one more key criterion: Allow no exceptions for external events. In fact, utility executives in Victoria specifically mentioned severe storms, load shedding, and shortfalls in generating capacity as external events for which the distribution company should remain liable. The regulator's thinking is that the distribution utility is in a better position to take action to mitigate the risk than individual customers are. "Such risks are better allocated to distributors than customers, given that distributors have greater capacity to mitigate their impact," says a review from the Office of the Regulator-General in Victoria.. "For example, distributors are better able to make decisions about the appropriate level of investment in network changes to reduce the impact of adverse weather. They are also better able to seek demand reductions when there is a material risk of load shedding."

\section{Markets Serving Individual Customers' Power Quality and Reliability Needs}

Customer power quality and reliability needs differ greatly. The basic level of service established by the regulator will not be adequate for all customers. Customers requiring greater reliability or increased power quality can take actions to obtain the level of service they require. Competitive markets minimize the cost and ensure customer choice in obtaining these services.

Customers can install equipment within their facilities to achieve any desired level of power quality and reliability they desire. Filters, surge protectors, UPSs, and backup generators are all available. Further, the customer can decide if it is necessary to increase the reliability or power quality for the entire facility, or if it is more cost-effective to address individual loads within the facility. This is inherently the customer's decision. Only the customer knows the Customers can install equipment within their facilities to achieve any desired level of power quality and reliability they desire. Much of the DER industry is dedicated to meeting the power quality and reliability needs of individual customers through market-based solutions. value of increased reliability or power quality for the customer's situation. Much of the DER industry is dedicated to meeting the power quality and reliability needs of individual customers through market-based solutions.

Though most of the serious economic impact from lower-than-needed power quality and reliability is in the commercial and industrial sectors, the residential sector provides examples that illustrate the problem and possible solutions. A typical home may have a number of high-power loads such as a heat pump, water heater, oven, dryer, refrigerator, and freezer. While none of these loads is 
particularly sensitive to momentary power interruptions, a few of the electronic loads within the home (e.g., digital clocks in the VCR, microwave, and oven) are sensitive to momentary interruptions. Yet these sensitive loads are an insignificant portion of the energy or power demand. It makes little sense to raise the power quality and reliability of the entire distribution feeder in order to serve these loads. It makes much more sense to either design the clocks with enough energy storage (a small capacitor) to ride through momentary interruptions, or to place the individual appliances on UPSs.

An interesting problem arises when the market fails to offer products that meet the customer's power quality needs. If a consumer cannot find a VCR that is designed to tolerate momentary power interruptions, for example, the customer may pressure the load-serving entity and the regulator to increase the power quality of the overall distribution system. This is understandable, but it is the wrong solution. It may be in the load-serving entity's interest to help the customer address the power quality and reliability problem locally. For residential customers, this could be through educational material provided in the bill. For industrial customers this could include engineering support.

\section{Some Customers Want Lower-Quality Service}

Some price-sensitive customers are more interested in reduced costs and are willing to accept lower levels of reliability than the level provided under the basic regulated service. These customers can "sell" interruption rights back to the power system. The T\&D company (or the energy supplier) would interrupt this customer when the system was under stress and thus avoid interrupting other customers. The T\&D company could use this capability to postpone a distribution system upgrade, for example. This concept does not work well for power quality, sags, and dips - as opposed to interruptions. It will be difficult for many customers to accept lower power quality in exchange for payment from the T\&D company.

\section{Transmission and Distribution Companies Providing Premium Power}

In many cases, the most cost-effective method for addressing the power quality and reliability needs of the customer is modifying the distribution system. An industry might desire a double-ended substation with two independent feeders to supply its load. It is entirely appropriate, and fairly easy, for the T\&D company to identify the additional costs involved in providing this type of aboveaverage service and to bill the customer for it. The customer is free to evaluate the T\&D solution against local generation, UPSs, and other commercially available alternatives.

Because the T\&D system is a communal asset that tends to provide the same level of service to all customers within a given area, having the system itself address individual issues regarding increased reliability and power quality can be problematic. The problem centers on the fact that the regulated entity may shift costs from the customers for which it is competing to other customers that are captive to its monopoly services. How could this happen? A T\&D utility that wants to sell premium power to an industrial customer could, for example, design $\$ 100,000$ of improvements to the distribution system and claim that $\$ 60,000$ of them are really supporting the system as a whole and should be placed in the regulated rate base. It would then offer the premium power solution to the industrial customer for $\$ 40,000$. It can be very difficult for someone on the outside, or even for regulators in some cases, to know if this split between the regulated $(\$ 60,000)$ portion and the competitive $(\$ 40,000)$ portion is appropriate.

Complications always arise when regulated and competitive markets interact. It is difficult for regulators to ensure that the monopoly customers they are charged with protecting are not being used to unfairly subsidize a competitive venture. Obviously, this subsidy would be viewed as unfair by the other companies competing to sell these products or services. But it also harms the regulated customers. First, they are harmed because their regulated rates are necessarily higher if they are subsidizing competitive ventures of the distribution company. Second, they are harmed again if the 
regulated company is able to use its unfair advantage to drive its competition out of business. Customer choice for the competitive service is then reduced, and prices will likely rise.

With this strong incentive not to allow regulated entities to deal in competitive services, why allow T\&D companies to sell premium power? The economic benefits of solving power quality problems on the distribution system can be so overwhelming that eliminating this option would seriously harm customers. It is often technically easier and cheaper to implement power quality and reliability enhancements on the distribution system rather than exclusively (or in conjunction with) within the customer's facility. This provides a strong argument for wanting to include T\&D companies in the mix of solution providers.

Adomaitis and Frank ${ }^{9}$ provide an excellent example of a case in which enhancing the T\&D system proved to be the most cost-effective way to address a power quality problem for a 15-MVA industrial customer. They describe a situation where a manufacturer of glass picture tubes was experiencing production problems and losses whenever a lightning storm occurred in the area. The manufacturing process requires maintaining tight tolerances and was sensitive to power quality. If the process is shut down in a disorderly fashion, hours or days may be required to restart and get production back within specification. Momentary power interruptions and voltage sags were causing such shutdowns. The customer had installed ride-through capability on the low-power devices. Ridethrough capability for the large motors was prohibitively expensive, however. A dynamic voltage regulator (DVR) solution was estimated to cost $\$ 4$ million. Supplying the plant directly from the $230-\mathrm{kV}$ system was also investigated, but this move, too, was found to be too expensive, at about $\$ 2.5$ million.

Allegheny Power studied the problem carefully and found that by installing lightning arresters every 600 to $800 \mathrm{ft}$ on approximately 50 miles of the $46-\mathrm{kV}$ subtransmission system (and recoordinating the protective relay scheme), they could eliminate the power quality problems. The solution cost approximately $\$ 400,000$ and was clearly the economically correct choice.

While this project is a beautiful example of why it is technically and economically important for distribution companies to be able to participate in supplying enhanced power quality, Adomaitis and Frank did not address several interesting commercial and regulatory concerns. Who should pay the $\$ 400,000$, for instance? Since the beneficiary was the picture tube manufacturer, should it pay the entire cost? Power quality on the entire regional $46-\mathrm{kV}$ sub-transmission system was raised, opening the argument that other customers who also benefited from the improved power quality should help pay for the project. But there is no indication that other customers in the area were dissatisfied with the level of service they were already receiving. Future customers, especially power-quality-sensitive customers, are also a concern. If another sensitive factory locates in the region, should it share in the cost of the upgrade and reduce the share the picture tube manufacturer is paying? (Reference 10 discusses a situation where the customer should pay to provide premium power to its own facility.) Should the regulator allow the cost of the enhancement to be spread among all customers on the theory that enhanced power quality will attract new industry and be good for the economic growth of the region in general? These difficult policy issues are intimately related to the technical differences in the technology choices.

The manufacturers of DVRs, for example, would be especially concerned with how these questions are answered. Had the economic trade-off between the DVR and T\&D solutions been closer, the decision could very easily have turned on who is paying how much. In fact, the picture tube manufacturer would likely favor the T\&D solution, even if it were more expensive, if the distribution company were able to spread the cost among other customers.

At least three important points can be drawn from this picture tube factory example: 
- The distribution solution can be the lowest cost, by a significant margin.

- The potential exists for the distribution company to cross-subsidize between regulated and competitive services - in fact it can be difficult to determine what the correct allocation between regulated and competitive services is.

- A free-rider problem exists.

\section{Ensuring That Market Forces Work to Provide Power Quality and Reliability}

This chapter shows that market forces can be used to address power quality and reliability requirements for both the majority of customers that are satisfied with basic service and for customers with special requirements. It is important to get the rules right, however, or the unintended consequences can be dire. Basic principles include these:

- Identify metrics to measure power quality and reliability.

- Establish a baseline for normal service. The baseline will likely be different for each utility and for different types of feeders.

- Establish a rate structure with incentives for the distribution utility to meet and exceed the power quality and reliability standards.

- Define premium power as service beyond the normal expectation.

Historically, detailed standards for power quality and reliability have not been well defined. There is a need for more disaggregated measures of power quality and for the focus of regulation to shift from the current standards that provide a safety net to targets for service quality that customers expect to receive. When this shift occurs, it will become possible to more clearly distinguish premium power from normal power. Regulated T\&D companies can then be allowed to sell premium power competitively, since the costs they incur to provide that service can more readily be distinguished from the regulated costs they incur to provide the normal regulated service. Concerns over crosssubsidies are thus greatly reduced. Without clear expectations for basic service power quality and reliability, it could appear that the T\&D company was intentionally suppressing the quality of basic service to increase sales of premium power. 


\section{References}

1. Electric Power Research Institute, Dynamics of Interconnected Power Systems, A Tutorial for System Dispatchers and Plant Operators, prepared by Power Technologies, Inc., Schenectady, N.Y., for the Electric Power Research Institute, Palo Alto, Calif., May 1989.

2. Gerald Heydt, Electric Power Quality, Stars in a Circle Publications, December 1991.

3. IEEE, "Probability Analysis of Power System Reliability," IEEE Tutorial, Course Text 71 M30PWR, 1971.

4. C. A. Warren, "A Nationwide Survey of Recorded Information Used for Calculating Distribution Reliability Indices,” IEEE Transactions on Power Delivery 18, no. 2 (April 2003).

5. Pacific Power, "Customer Service Commitments: Annual Report," May 2003, available at http://www.pacific-power.com/File/File28086.pdf.

6. Dennis Hansen, A Methodology for Maintaining and Improving Reliability, IEEE 0-7803-72859/01, Institute of Electrical and Electronic Engineers, Piscataway, N.J., 2001.

7. Richard E. Brown, Distribution Reliability Modeling at Commonwealth Edison, IEEE 0-78037285-9/01, Piscataway, N.J., 2001.

8. 2001 Electricity Distribution Price Review, Draft Decision, Office of the Regulator-General, Victoria, Melbourne, Australia, May 2000, 15601.

9. J. Reese Adomaitis and Fred F. Frank, Use of Surge Arresters in Place of Static Wires to Reduce Lightning Caused Voltage Sags on Subtransmission Systems, Allegheny Power, Engineering Development and Support, Greensburgh, Pa., 1997.

10. Jim Evans, "Big Three Automakers Get What They Pay For," Transmission and Distribution World, December 1999. 



\section{Appendix A \\ Terms and Definitions of Reliability}

\section{Major Sources for Terms and Definitions}

The following is a list and brief synopsis of many of the major sources for terms and definitions of reliability and service quality. This list is not intended to capture every single definition, but rather, the important ones that are in common use or practice today.

IEEE Tutorial Course: "Probability Analysis of Power System Reliability," Course Text 71 M30PWR (1971)

Organization: The Institute of Electrical and Electronics Engineers (IEEE)

Targeted industry segment: Utility power system planners-bulk power and distribution systems Limitations: This defines the terms and introduces the calculation techniques for power system reliability indices, but it does not address variations in methods for calculating the indices. As an older reference, it is not current on some reliability issues, such as demand-side management. Power quality is not addressed.

Strengths: It introduces concepts of power system reliability and provides consensus definitions of reliability terms and indices.

IEEE Std. 1366-1998: Trial Use Guide for Electric Power Distribution Reliability Indices Organization: IEEE

Targeted industry segment: Utility distribution systems and substations and defined regions Limitations: This standard deals primarily with interruptions over one minute and defines such indices as SAIFI (system average interruption frequency index), SAIDI (system average interruption duration index), and CAIDI (customer average interruption duration index). The indices are concerned with both the duration and frequency of interruption.

Strengths: These are the indices that are commonly reported in reliability surveys. The standard shows the mathematical definition of the indices and gives examples of their calculation.

Other: Although these are the most common indices, they do not include the voltage sag and dip disturbances that are so troubling to digital equipment. Also, there is a great deal of debate about comparing these indices from one geographic area to another, because rural areas, or areas with high lightning activity, are expected to have a higher number of outages than densely populated urban areas with network distribution systems, for example.

IEEE Std. 762: Definitions for Use in Reporting Electric Generating Unit Reliability, Availability and Productivity

Organization: IEEE

Targeted industry segment: Utility power system planners

Limitations: Does not treat intermittent generation, as from renewable sources (wind, solar), according to the generally accepted method.

Strengths: Defines and classifies parameters for use in generation availability reporting. Terms such as "maximum capacity," "planned derating," and "forced outage hours" are defined.

IEEE Std. 859-1987: Standard Terms for Reporting and Analyzing Outage Occurrences and Outage States of Electrical Transmission Facilities

Organization: IEEE

Targeted industry segment: Transmission system modeling and reliability evaluation

Limitations: The standard provides outage definitions and indices that are intended for use in system planning models, operations and maintenance planning, and system design. It is not intended to 
provide guidance on how to perform quantitative evaluations of system reliability, and it provides no guidance other than to give definitions for key indices.

Strengths: The standard provides the definitions of a number of common transmission indices such as "outage rate," "failure rate," and "mean time to outage."

Other: The standard also provides definitions for terms such as "component availability" and "probability of failure to operate on command." These indices are used by engineers involved in analyzing and predicting outages of transmission facilities.

IEEE Std. 493-1997: Recommended Practice for Design of Reliable Industrial and Commercial Power Systems (IEEE Gold Book)

Organization: IEEE

Targeted industry segment: Industrial and commercial electric power distribution systems. This standard could be used for microgrids.

Limitations: This standard is directed toward the designers and users of industrial power systems. It is not intended for utility distribution or transmission systems.

Strengths: The standard provides historical component reliability data that can be used in a quantitative evaluation of the industrial power system to compute load interruption frequency, expected duration of load interruption events, total expected interruption time per year, and system availability as measured at a specific load supply point.

Other: The method used for the evaluation is the minimal-cut-set method. System weak points can readily be identified.

Electricity Distribution Price Review—Reliability Service Standards, working document to benchmark Australian utility service quality Organization: Office of the Regulator General, Australia

Targeted industry segment: Australian utilities and their customers

Limitations: This is an ongoing activity; therefore, the standards being developed are not yet available to the general public.

Strengths: The objective of this activity is to develop performance-based rates, including both reliability and service quality, by applying IEEE 1366 and monitoring the performance of distribution feeders. Observed levels of reliability and power quality will be used to establish benchmarks for feeders (by type of feeder and types of customers served) to set service quality targets. The utility's incentive to meet or exceed the targets is through performance-based rates. This is an important attempt to apply indices to setting service quality and reliability standards, relating system performance to price (tariffs), and establishing benchmark levels for power system performance that are related to characteristics of the customers being served.

Other: The Electric Power Research Institute (EPRI) is developing a similar approach for U.S. utilities that goes beyond performance-based rates and IEEE 1366 to a QRA approach (see "Assessing and Evaluating Reliability," in Chapter 2).

State of Illinois: Title 83 Public Utilities, Chapter 1: "Illinois Commerce Commission," Subchapter C: "Electric Utilities," Part 411, "Electric Reliability"

Organization: Illinois Commerce Commission

Targeted industry segment: Illinois utilities

Limitations: Code language for the state of Illinois. Does not specify reliability levels: "design according to generally accepted engineering practices." The utility is required to state what those practices are.

Strengths: Defines reliability terms and record-keeping requirements for Illinois utilities. Classifies outage causes, defines procedures and formats for annual reliability reports and assessments.

Other: Unique to one state's requirements 
Emerald Contract: power supply contract under the "Green Rate"

Organization: Electricite de France (EdF)

Targeted industry segment: Green Rate customers of EdF

Limitations: The topology of the French power system, particularly the distribution system, is unlike

that of the U.S. power system. Also, EdF is a government-owned, vertically-integrated monopoly; it

doesn't operate in the same type of competitive environment as U.S. utilities. (However, European

union rules on competition and third party access may change this.) This is a contract of a single

utility.

Strengths: The contract contains an appendix that lists disturbances that may affect the quality of electric power, includes simplified definitions, and delineates EdF commitments and minimum acceptable levels of service quality and reliability. It also specifies the tolerances with which the customer should comply concerning disturbances generated by customer-owned equipment that could be injected into the EdF network.

Other: Provides an example of service quality commitments from the utility to the customer and requirements imposed upon the customer by the utility. Even if the numbers are not directly applicable to the United States, this approach could be applicable.

Quality of Supply Standards, User Specification, ESKOM, South Africa, NRS 048-1996

Organization: ESKOM and South Africa's National Electricity Regulator

Targeted industry segment: Electric utility and customers

Limitations: This is one utility's guideline, applied to a non-U.S. power system.

Strengths: This specification provides the South African electricity supply industry with a basis for evaluating the quality of supply delivered to customers by the industry, and with a means of determining whether utilities meet the minimum standards required by the National Electricity Regulator. The underlying principle is that, on a national basis, the combined cost of supply and usage of electricity be minimized. The specification recognizes that quality is affected by the users (as a result of the nature of the loads connected), as well as by the producers or suppliers. Customers are therefore essential partners with utilities in the effort to maintain the quality of supply while the supply networks are expanded and developed to allow electrification of South Africa to proceed effectively and economically. The specification deals with the voltage characteristics in statistical or probabilistic terms. NRS 048 provides an overview of standards and procedures for the management of the quality of supply in the electricity supply industry, with particular reference to the application of minimum standards to meet the requirements of the National Electricity Regulator. NRS 048 does not cover safety requirements, network design or equipment performance.

\section{Reliability and Power Quality Performance-based Tariffs}

Organization: DTE Energy (Detroit Edison Company)

Targeted industry segment: Three large industrial customers

Limitations: This is one utility's strategy to retain customers by guaranteeing that the power supply system will meet performance criteria. Manufacturing facilities of the Big Three automakers had experienced higher-than-normal outages and voltage sags that had resulted in significant manufacturing losses. Faced with the possibility that these customers would turn to another energy supplier or self-generate, DTE offered a performance guarantee. The initial contract specified that DTE would pay stipulated "damage" costs to customers if they experienced more interruptions than specified in the contract. This performance guarantee was later expanded to include instances of voltage sags (i.e., power quality). DTE implemented measures to improve the reliability, and the resulting performance has almost completely met the reliability criteria. The power quality criterion has not been violated. The criteria were set based on historical performance, with an assumed yearby-year reliability improvement. The utility did a reliability assessment for each plant, and since existing problems or weak points were corrected, the plants' reliability has been acceptable. The corrective actions seemed consistent with standard utility practices to provide acceptable quality of 
service; it appears that the tariff and its penalty levels were designed more on a marketing basis than from a cost analysis. The tariff (1) retained the customers and protected DTE from competition for 5 years, (2) was used to economically justify reliability improvements that might have been within current best practices anyway, and (3) has not resulted in any significant performance payments to the customers.

Strengths: Despite its limitations, this is the first well-documented instance of service quality guarantees being included in customer agreements that recognized the utility's obligation to meet at least a minimum level of reliability and power quality.

Other: The concept of performance-based rates and service quality guarantees seems to be gaining acceptance by utilities and regulators.

\section{Other Sources for Terms and Definitions}

Several sources define terms such as "sag," "notch," "undervoltage," and "swell," but not always consistently. Some of the more prominent references are these:

- IEEE Std. 100-1988, IEEE Standard Dictionary of Electrical and Electronic Terms

- IEEE Std. 1100-1999, IEEE Recommended Practice for Powering and Grounding Electronic Equipment

- IEEE Std. 1159-1995, IEEE Recommended Practice for Monitoring Electrical Power Quality

- American National Standards Institute/National Fire Protection Association, Standard 70, National Electric Code

- B. Kennedy, Power Quality Primer, New York: McGraw Hill, 2000

Organizations: Various organizations

Targeted industry segment: All in the power industry, including consumers, designers and electricians Limitations: Terminology and definitions are still evolving, both within the United States and internationally, although there are attempts to make U.S. definitions consistent with international [International Electrotechnical Commission (IEC)] definitions. A major problem has been inconsistencies among utility power system designers, industrial power distribution designers, and end users. The rise in electronic loads ("the digital society") means that some power system phenomena that previously were of no consequence are now critically important to the end users' processes or can threaten personnel safety. There is not yet a single recognized standard for definitions and calculation techniques, but many industry groups are working together to remedy this situation.

Strengths: The references cited will provide a good foundation for power quality terminology. The Power Quality Primer provides an excellent overview of power quality concerns for both the provider and consumer.

Other: Industry groups, such as IEEE, are close to agreement on common terminology and definitions. Some of these standards (i.e., 1100, 1159) are listed again in the Power Quality Standards, as they provide requirements or guidelines in addition to definitions. 


\section{Appendix B Power Quality Standards, Guidelines, and Measurement}

The following is a list and brief synopsis of many of the standards for power quality. Again, this list is not intended to capture every single standard, but rather the significant ones that are often invoked or referenced currently.

IEEE Std. 141-1995: Red Book IEEE Recommended Practices for Electric Power Distribution for Industrial Plants

Organization: IEEE

Targeted industry segment: Industrial and commercial facilities

Limitations: This standard is directed more towards good electrical power engineering practice and is not focused on power quality.

Strengths: A thorough analysis of basic electrical systems is presented. Guidance is provided in design, construction, and continuity of the overall system.

Other: Recommendations are made regarding system planning, voltage considerations, surge voltage protection, flicker, protective devices, grounding, and other issues.

IEEE Std. 519-1992: IEEE Recommended Practices and Requirements for Harmonic Control in Electrical Power Systems

Organization: IEEE

Targeted industry segment: Industrial and commercial power systems with non-linear loads

Limitations: This standard addresses steady-state operation only, and not transients.

Strengths: The practices are used for guidance in the design of power systems with non-linear loads, such as adjustable speed drives and uninterruptible power supplies.

Other: The standard also discusses power system response characteristics, the effects of harmonics, methods for harmonic control, and recommended limits.

IEEE Std. 1159-1995: IEEE Recommended Practice for Monitoring Electric Power Quality Organization: IEEE

Targeted industry segment: Utilities and industrial and commercial power systems

Limitations: This standard deals with electromagnetic disturbances such as voltage dips, notching, oscillatory transients, and frequency variations.

Strengths: The standard provides guidance in the monitoring, classification, and correction of a wide range of steady state and transient phenomena. It defines disturbances in 24 categories of typical characteristics of power system electromagnetic phenomena.

Other: The standard provides guidance on troubleshooting, interpreting data, analysis tips, and verifying the solution. Some IEEE groups developing sections of this standard are the following:

IEEE P1159.1 Task Force on Recorder Qualification and Data Acquisition Requirements for Characterization of PQ Events

This task force is developing the Guide for Recorder and Data Acquisition Requirements for Characterization of Power Quality Events. This guide will establish the data acquisition attributes necessary to characterize the electromagnetic phenomena listed in Table 2 of IEEE Std. 1159-1995. The guide includes definitions (in conjunction with P1433), instrumentation categories, and technical requirements that are related to the type of disturbance to be recorded. The objective of this guide is to describe the technical measurement requirements for each type of disturbance in Std 1159-1995. Measurement requirements of these types of disturbances are not currently covered by other standards. 


\section{IEEE P1159.2 Task Force on Characterization of a Power Quality Event}

This task force is developing a recommended practice for converting a suitably sampled voltage and current data set into specific power quality categories. Appropriate definitions, categories, and sampling rates are being developed by other task forces. The emphasis is on compatibility between power delivered by power suppliers and power needed by equipment manufacturers. The translation from sets of digital data to statistically comparable events could be used for comparing power suppliers, comparing susceptibility qualities of equipment, and evaluating performance vs specification or contract.

IEEE P1159.3 Task Force on the Transfer of Power Quality Data

This task force is developing a recommended practice for a file format suitable for exchanging power-quality-related measurement and simulation data in a vendor-independent manner. (Definitions and event categories are being developed by other task forces.) Many simulations and measurement and analysis tools for power quality engineers are available from numerous vendors. Generally, the data created, measured, and analyzed by these tools are incompatible among vendors. The proposed file format will provide a common ground to which all vendors could export and from which they could import to allow the end user maximum flexibility in choice of tool and vendor.

IEEE Std. 1100-1999: Recommended Practice for Powering and Grounding Electronic Equipment (Emerald Book) Organization: IEEE

Targeted industry segment: Industrial and commercial electric power distribution systems. Limitations: This standard is directed toward the designers and users of industrial power systems. It is not intended for utility distribution or transmission systems.

Strengths: The standard provides information on the electrical environment, conducting power surveys, monitoring and metering equipment, power conditioning equipment, and wiring and grounding for power quality. Historically, most power quality problems in an industrial environment resulted from improper wiring or grounding. The standard has been revised to include additional information on the sensitivity of industrial environments.

IEEE 1250-1995 IEEE: Guide for Service to Equipment Sensitive to Momentary Voltage Disturbances

Organization: IEEE

Targeted industry segment: Utilities and industrial and commercial power systems.

Limitations: The purpose of this guide is to assist in identifying potential problems and to suggest effective ways to satisfy sensitive equipment voltage problems.

Strengths: The guide describes many common problems, such as capacitor switching, motor starting, and tap changing.

Other: The guide provides data on various types of sensitive loads-including computers, process control, and adjustable speed drives - and suggests solutions and measures, such as grounding, circuit design, and surge protection.

IEEE Std. 1346-1998: IEEE Recommended Practice for Evaluating Electric Power System Compatibility with Electronic Process Equipment Organization: IEEE

Targeted industry segment: Utilities and industrial and commercial power systems.

Limitations: This standard deals with planning and designing a power supply system so that compatibility issues with electronic process equipment are resolved.

Strengths: The standard provides guidance in methods for analysis of power systems in evaluating the compatibility of service quality with the equipment that uses the electricity. This standard addresses 
the issue of how service quality affects the end user. The standard provides worksheets to provide an estimate of the number of disruptions, financial loss, and analysis of alternatives.

Other: This first edition of the standard provides a methodology for voltage sags; later editions will deal with issues such as harmonics and transients. The purpose of this document is to recommend a standard methodology for the technical and economic analysis of compatibility of process equipment with the electric power system. The emphasis is on the new digital loads of microprocessors and power electronics equipment. This document does not intend to set performance limits for utility systems, power distribution systems, or electronic process equipment. Rather, it shows how the performance data for each of these entities can be analyzed to evaluate their compatibility in economic terms. The recommended methodology will also provide standardization of methods, data, and performance of power systems and equipment in evaluating compatibility so that compatibility can be discussed from a common frame of reference. The methodology is intended to be applied at the planning or design stage of a system; consequently, it does not discuss troubleshooting or correcting existing power quality problems. [See http:/grouper.ieee.org/groups/1346/. index.html, IEEE Electric Power System Compatibility with Electronic Process Equipment (P1346).]

IEEE Std. P1564 IEEE: Recommended Practice for the Establishment of Voltage Sag Indices Organization: IEEE

Targeted industry segment: Utilities and industrial and commercial power systems.

Limitations: This is a draft standard in preparation. It will provide sag indices to indicate the different performance levels at the transmission, substation, and distribution circuit levels.

Strengths: The standard will provide guidance in characterizing sags in terms of indices.

Other: The standard should help utilities and manufacturers compute the advantages and disadvantages of various connections to the electrical system.

CBEMA Curve and IEEE Standard 446-1995: IEEE Recommended Practice for Emergency and Standby Power Systems for Industrial and Commercial Applications (Orange Book) Organization: Computer Business Equipment Manufacturers Association (CBEMA) and IEEE Targeted industry segment: Computer manufacturers, building electrical system designers. Limitations: Criteria for tolerance of computer equipment to voltage variations. The CBEMA curve has been applied to many types of electronic equipment and needs to be updated to reflect current state-of-the-art of electronic equipment.

Strengths: This is a widely accepted and recognized standard.

Other: The CBEMA Curve is a part of IEEE 446. Cognizant industry groups are involved in updating the curve and specifying the situations where it is applicable. The CBEMA curve is discussed further in Chapter 3 of this report under "A Basic Generally Accepted Level of Reliability." 



\title{
Appendix C \\ Activities and Organizations Developing and Sharing Information on Reliability and Power Quality
}

The following is a list and brief synopsis of the many organizations that have ongoing activities in power quality or reliability. Again, this list is not intended to capture all organizations, but rather the significant ones that are presently involved in examining power quality.

\author{
North American Electric Reliability Council (NERC)—North American Electric Reliability \\ Organization (NAERO) \\ Organization: NERC \\ Targeted industry segment: Utilities, state regulatory agencies. \\ Strengths: In 1997, NERC began a self-assessment activity to examine how best to ensure adequate \\ reliability of electric power under the new, competitive structure of the North American electric \\ utility industry. NERC is a voluntary member organization comprising regional reliability councils. \\ The recommendation is to establish a successor organization, NAERO, with a similar structure but \\ charged with developing a mandatory set of guidelines. Unlike NERC, NAERO will have the \\ authority to enforce compliance with its guidelines. \\ Limitation: This activity is just beginning.
}

Self-Assessment Template, Power Delivery Reliability Initiative, EPRI Distribution Program, Level 2 report, April 2001

Organization: EPRI

Targeted industry segment: EPRI member utilities.

Limitations: This is a report of continuing research, not a final technical report. It is intended for EPRI member utilities that have contributed to this specific research target; the report is not available to the entire industry.

Strengths: This is a broad-based and comprehensive effort to develop data on levels of distribution system reliability (as seen by the customer) and causes of outages. This is a template for assessing practices at distribution companies and therefore is a precursor to the development of reliabilityrelated best practices.

Other: EPRI is assembling a database of utilities' responses to the template. The project includes a Web link for users to ask EPRI about industry practices or suggest enhancements to the template. EPRI has a similar activity to assess transmission system reliability.

Transmission Reliability Project, EPRI Transmission Program

Organization: EPRI

Targeted industry segment: Transmission planners of EPRI member utilities.

Limitations: This is continuing research project. It is intended for EPRI member utilities that have contributed to this specific research target; the report is not available to the entire industry. Strengths: The Transmission Reliability Project takes a grid-wide approach to power system reliability, recognizing the regional interconnected structure of the U.S. transmission system. Its objective is the development of an improved probabilistic risk assessment technique that models the grid's physical and operating margins probabilistically, rather than deterministically (as is now general practice). This is a first step in developing improved reliability-related best practices for transmission planning and operations.

Other: This is an on-going research activity and will not provide definitive results for several years. EPRI has a similar activity to assess distribution system reliability. 
Assessment of Distribution System Power Quality, EPRI Research Project PR3098-1

Organization: EPRI

Targeted industry segment: EPRI member utilities.

Limitations: Reports distribution system power quality observations from a limited number of

utilities. The full reports are available only to EPRI members. However, summary statistics have been published in open literature.

Strengths: Multi-year power quality statistics are given for more than 300 points on the distribution systems of 34 utilities. The summary statistics provide a large sample of power quality performance on utility systems throughout the United States. The database has the capability to correlate observed levels of power quality with utility, weather, geography, feeder topology, and customer characteristics.

Other: This project is ongoing and provides the broadest sample of U.S. distribution system power quality statistics. It is a necessary first step in setting power quality standards.

\section{IEEE Power Quality Activities}

This item lists some additional power quality groups within IEEE. IEEE groups are updating or developing some of the previously listed standards - 1159 and 1346 - as well as other related standards.

Organization: IEEE

Targeted industry segment: Utilities, vendors, equipment designers, systems designers.

Limitations: Voluntary organization; limited outreach to organizations and individuals not in IEEE; coordination among IEEE groups is critical because of the different constituencies (IEEE Standards Coordinating Committee SCC-22 is attempting to do this).

Strengths: Consensus standards; broad-based constituency

\section{IEEE SCC-22 - Standards Coordinating Committee on Power Quality}

SCC-22 is responsible for coordinating IEEE activities relating to power quality. In addition to coordinating the following activities, SCC-22 is the designated IEEE liaison with any other standardsdeveloping bodies that are preparing power quality standards or guidelines.

\section{IEEE P1409 Distribution Custom Power Task Force}

This task force is developing the Guide for Application of Power Electronics for Power Quality Improvement on Distribution Systems Rated $1 \mathrm{kV}$ through $38 \mathrm{kV}$. The document will provide guidelines and performance expectations for the application of power electronics-based equipment on utility distribution systems for improving power quality and control in these distribution systems. The guide will be a resource to utilities in the competitive marketplace, providing detailed information about custom power devices as options for solving power quality problems.

\section{P1453 IEEE Voltage Flicker Task Group}

This task force is developing a recommended practice for a measurement protocol for and limits to voltage flicker. The task force has voted to adopt and enhance the IEC Flickermeter measurement protocol.

\section{IEEE Working Group on Surge Characterization}

This working group completed a set of documents on surge characterization and test procedures:

C62.41.1 - Guide on the surge environment in low-voltage ac power circuits

C62.41.2 - Recommended practice on surge characterization in low-voltage ac power circuits

C62.45-Recommended practice on surge testing for equipment connected to low-voltage ac power circuits 


\section{Other IEEE working groups}

PC62.44 - Applications guide on secondary arresters

PC62.72 - Low-voltage ac power circuit protective devices

PC62.74 - Application guide for multi-port protectors

\section{National Association of Regulatory Utility Commissioners (NARUC) \\ Organization: NARUC \\ Targeted industry segment: State regulators.}

Limitations: It is difficult to address all of the reliability issues

Strengths: NARUC has a staff subcommittee on Electric Reliability that is working to develop standard reliability assessment techniques (and identifying how to enhance reliability). This activity is providing guidance to regulators who traditionally do not have extensive expertise in power system reliability and is helping to standardize evaluation procedures among states.

\section{American Public Power Association (APPA), Distribution System Performance Improvement Guide Organization: APPA \\ Targeted industry segment: Publicly-owned utilities, technical and engineering staff.}

Strengths: This is a companion guide to APPA's Making the Most of Your Distribution System, which was targeted to policymakers. It provides step-by-step procedures for evaluating distribution system performance and comparing performance improvement options. The report contains several case studies. It covers many aspects of utility operations, not just reliability. APPA has asked members to report outages consistent with IEEE P1366. APPA has conducted statistical surveys of the SAIDI and CAIDI but has found that these numbers cannot be compared because of differences among member utilities in how outages are defined (i.e., the problem is in defining what is an outage, not in how SAIDI is calculated). APPA has published the Distribution System Performance Improvement Guide and Distribution System Optimization Guide, consisting of selected case studies that illustrate how its members address this issue. This is the first attempt to assemble a comprehensive reliability performance database for public utilities.

Limitations: Voluntary reporting is not complete; there are different data definition and reporting procedures.

\section{Maintenance Guidelines, Requirements Study Format}

Organization: U.S. Department of Agriculture, Rural Utilities Service (RUS)

Targeted industry segment: Rural electric cooperatives.

Description and strengths: To qualify for a loan from RUS, a utility must submit a 5-year requirements study, including a Load Forecast, a Construction Work Plan, and a Long-Range Plan. RUS does not have a required format for these documents, but guidelines for their submission are on the RUS Web site, and data requirements are given in 7 CFR 1710. RUS is also instituting a Webbased data reporting system. The cooperatives' plans must be updated every year for transmission projects and every 3 years for distribution projects. The cooperative must also follow the RUS maintenance guidelines, outlined in Bulletin 1730-1 Electric System Operation and Maintenance. This bulletin contains guidelines related to electric borrowers' operation and maintenance (O\&M) and outlines the RUS standard practices with respect to review and evaluation of O\&M practices. While RUS does not have a reliability standard, the intent is that adhering to these loan conditions will result in a plan that provides an acceptable quality of service. For construction design criteria, RUS usually uses ANSI standards as requirements for cooperatives' projects, but RUS has a more conservative standard than ANSI for transformers. Standard practices (e.g., in design, construction) across the country mean that a lineman from any cooperative can recognize (and help) any other cooperative. Design standards, lists of acceptable materials and equipment, and more detailed information can be found on the RUS Web site at www.usda.gov/rus. 
Limitations: These are general requirements and guidelines for utility practices and construction standards for cooperatives applying for loans from RUS. RUS does not impose a reliability standard. RUS also sees different problems - and solutions - for rural vs urban cooperatives.

\section{NRECA Reliability and Power Quality Assessment}

Organization: National Rural Electric Cooperative Association (NRECA), Cooperative Research Network (CRN)

Targeted industry segment: Rural electric cooperatives.

Description and strengths: NRECA feels that many industry guidelines - such as the IEEE reliability indices and definitions and the EPRI reliability performance studies - are not applicable to rural cooperatives, or even rural parts of electric utility service territories in general. Rural customers have different needs, expectations of quality and availability of service, ways to cope with service interruptions, and access problems from the typical urban customer. As a remedy, the CRN is undertaking a comprehensive look at reliability and power quality for rural areas to (1) develop reliability and power quality indices that apply to rural systems, (2) conduct benchmarking of reliability and power quality performance, and (3) identify relevant case studies. The intention is to eventually be able to develop recommended levels of reliability and power quality for rural systems based on the benchmarking work. This project is expected to be completed by the end of 2002 . Through the CRN, NRECA also has developed several operations guidelines to improve system reliability for rural cooperatives. (These reports cover specific topics such as vegetation management.) Additional information can be obtained directly from NRECA or on the CRN Web site at http://www.crnweb.org/.

Limitations: The reports are available only to CRN members.

\section{International and European Organizations}

Several European electric utility organizations have working groups developing power quality specifications:

Congress Internationale des Grand Reseaux Electriques a Haute Tension (CIGRE)—Working Group 36.05 on voltage quality

Congress Internationale des Reseaux Distribution (CIRED)—Working Group 2, joint with CIGRE Working Group 36.05

UNIPEDE/Eurelectric - Working groups on voltage limits, electromagnetic compatibility, harmonics Targeted industry segment: Utilities, regulators.

Strengths: Broad-based participation from European countries.

Limitations: European practices and designs are not always compatible or consistent with those in the United States.

\section{Reports on Electric Power Disturbances}

Organization: Federal Energy Regulatory Commission (previously, Federal Power Commission, Energy Regulatory Agency)

Targeted industry segment: Utilities and regulatory agencies.

Limitations: These are summary reports of major outages. The information is not very detailed regarding the numbers of customers affected, duration of outages, and amount of load interrupted. The format is especially limiting for assessing partial restoration after the incident. However, the biggest limitation is that only major bulk power outages are included; events affecting fewer customers or for short durations may not be reported.

Strengths: Provides data on large outages in the United States over the last 30 years.

Other: Provides a historical perspective on U.S. power system reliability. 
Scoping Study on Trends in the Economic Value of Electricity Reliability to the U.S. Economy Organization: Consortium for Electric Reliability Technology Solutions (CERTS) http://certs.lbl.gov Targeted industry segment: Utilities, industries, electrical consumers.

Limitations: This is a scoping study prepared using a literature review and the other available data with direction from EPRI. It is a step toward understanding the cost impact to the U.S. economy of unreliable electricity, how the value of reliability is likely to change in the future, and how customers are addressing their reliability needs.

Strengths: This study provides an analysis of trends in the economic value of electricity reliability in the U.S. economy. The analysis includes requirements of commercial office equipment, statistical indicators of industrial electricity use and economic activity to identify high-reliability market segments, and a case study of a market segment known to have high-reliability requirements.

\section{Office of Electric Transmission and Distribution}

Organization: Office of Electric Transmission and Distribution, U.S. Department of Energy Targeted industry segment: Utilities, regulatory agencies, vendors, customers.

Purpose: This office is an in-depth resource for the many aspects of transmission and distribution reliability. One of the first reports is the National Transmission Grid study, available at http://www.ntgs.doe.gov. 



\section{Appendix D Summary Table: Power Quality Standards Development Activities}

Table 2, provided by courtesy of EPRI-Power Electronics Applications Center, provides a listing of various power quality topics, the standards body working on the topic, the project reference, and the subject of the document.

Table 2. Power quality topics and related documents

\begin{tabular}{|c|c|c|c|}
\hline $\begin{array}{l}\text { Power quality } \\
\text { topic }\end{array}$ & Standards body & $\begin{array}{l}\text { Project ID } \\
\text { references }\end{array}$ & Title or subject of document \\
\hline \multirow[t]{3}{*}{$\begin{array}{l}\text { Adjustable } \\
\text { speed drives }\end{array}$} & IEEE PES & P958 & $\begin{array}{l}\text { Guide for Application of AC Adjustable Speed } \\
\text { Drives for Electric Generating Stations }\end{array}$ \\
\hline & IEC SC22G & WG5 & $\begin{array}{l}\text { Standard for specifications of rated values, service } \\
\text { conditions, performance criteria, efficiency } \\
\text { determination and test procedures for large high- } \\
\text { voltage adjustable-speed ac drive systems. }\end{array}$ \\
\hline & NEMA & ICS-7 & Adjustable Speed Drives \\
\hline Custom power & IEEE PES & P1409 & $\begin{array}{l}\text { Guide for Application of Power Electronics for } \\
\text { Power Quality Improvement on Distribution } \\
\text { Systems Rated } 1 \mathrm{kV} \text { through } 38 \mathrm{kV}\end{array}$ \\
\hline $\begin{array}{l}\text { Distributed } \\
\text { resources }\end{array}$ & IEEE-SCC21 & P1547 & $\begin{array}{l}\text { Distributed Resources and Electric Power Systems } \\
\text { Interconnection }\end{array}$ \\
\hline \multirow[t]{4}{*}{$\begin{array}{l}\text { Equipment } \\
\text { compatibility }\end{array}$} & IEEE SCC22 & P1346 & $\begin{array}{l}\text { Electric Power System Compatibility with } \\
\text { Electronic Process Equipment }\end{array}$ \\
\hline & IEEE EMC & P1560 & $\begin{array}{l}\text { Standard method for measurement of radio } \\
\text { frequency interference }\end{array}$ \\
\hline & IEC SC77A & $\begin{array}{l}61000-2-2 \\
61000-2-4\end{array}$ & $\begin{array}{l}\text { Compatibility levels for low-frequency conducted } \\
\text { disturbances and signaling in public low-voltage } \\
\text { power supply systems } \\
\text { Compatibility levels in industrial plants for low- } \\
\text { frequency conducted disturbances }\end{array}$ \\
\hline & ITIC & TC-3 & CBEMA Curve and Application Note \\
\hline \multirow[t]{3}{*}{ Flicker } & IEEE PES & P1453 & $\begin{array}{l}\text { Recommended practice for measurement protocol } \\
\text { and limits to voltage flicker }\end{array}$ \\
\hline & IEC SC77A & $61000-4-15$ & $\begin{array}{l}\text { Limitation of voltage changes, voltage fluctuations } \\
\text { and flicker in public low-voltage supply systems, } \\
\text { for equipment with rated current }<=16 \text { A per } \\
\text { phase and not subject to conditional connection } \\
\text { Amendment to add specifications for flicker } \\
\text { meters for } 120-V \text { systems and more closely define } \\
\text { the specification of a filter in the instrument }\end{array}$ \\
\hline & UIE WG2 & Part V & $\begin{array}{l}\text { Guide to Quality of Electrical Supply for Industrial } \\
\text { Installations-Flicker }\end{array}$ \\
\hline \multirow[t]{2}{*}{ Harmonics } & IEEE PES & New item & $\begin{array}{l}\text { Standards and guides for the application of low- } \\
\text { voltage active filters }\end{array}$ \\
\hline & $\begin{array}{l}\text { IEEE } \\
\text { PES/IAS/SCC22 }\end{array}$ & 519 & $\begin{array}{l}\text { Standard Practices and Requirements for } \\
\text { Harmonic Control in Electrical Power Systems } \\
\text { Guide for Applying Harmonic Limits on Power } \\
\text { Systems }\end{array}$ \\
\hline
\end{tabular}




\begin{tabular}{|c|c|c|c|}
\hline & IEC SC77A & 61000-4-7 & $\begin{array}{l}\text { Rationale for determining limits for mains } \\
\text { harmonic and interharmonic current emissions } \\
\text { Limits for interharmonic current emissions } \\
\text { (equipment with input power }<=16 \text { A per phase } \\
\text { and prone to produce interharmonics by design } \\
\text { Limits for harmonic currents produced by } \\
\text { equipment connected to public low-voltage } \\
\text { systems with input current }<75 \text { A per phase and } \\
\text { subject to restricted connection. } \\
\text { Testing and measurement techniques_-general } \\
\text { guide on harmonics and interharmonics } \\
\text { measurements and instrumentation, for power } \\
\text { supply systems and equipment connected thereto } \\
\text { Testing and measurement techniques-harmonics } \\
\text { and interharmonics including mains signaling at ac } \\
\text { power port, low frequency immunity }\end{array}$ \\
\hline $\begin{array}{l}\text { Interruptions } \\
\text { (see also under } \\
\text { "Sags") }\end{array}$ & IEC SC77A & $\begin{array}{l}61000-4-11 \\
61000-2-2 \\
61000-2-4\end{array}$ & $\begin{array}{l}\text { Voltage dips, short interruptions, and voltage } \\
\text { variations immunity tests } \\
\text { Compatibility levels for low-frequency conducted } \\
\text { disturbances and signaling in public low-voltage } \\
\text { power supply systems } \\
\text { Compatibility levels in industrial plants for low- } \\
\text { frequency conducted disturbances }\end{array}$ \\
\hline \multirow[t]{5}{*}{ Measurements } & \multirow[t]{3}{*}{ IEEE SCC22 } & TF 1159.1 & $\begin{array}{l}\text { Guide for Recorder and Data Acquisition } \\
\text { Requirements for Characterization of PQ Events }\end{array}$ \\
\hline & & TF 1159.2 & $\begin{array}{l}\text { Recommended Practice for Characterization of a } \\
\text { PQ Event }\end{array}$ \\
\hline & & TF 1159.3 & Recommended Practice for Transfer of PQ Data \\
\hline & IEC SC77A & WG09 & Measurements of PQ Parameters \\
\hline & UNIPEDE & Norcomp 87 & Measurement Guide for Voltage Characteristics \\
\hline \multirow[t]{3}{*}{$\begin{array}{l}\text { Sags (US) } \\
\text { Dips (IEC) }\end{array}$} & IEC & $\begin{array}{l}61000-4-11 \\
61000-2-2 \\
61000-2-4\end{array}$ & $\begin{array}{l}\text { Voltage dips, short interruptions, and voltage } \\
\text { variations immunity tests } \\
\text { Compatibility levels for low-frequency conducted } \\
\text { disturbances and signaling in public low-voltage } \\
\text { power supply systems } \\
\text { Compatibility levels in industrial plants for low- } \\
\text { frequency conducted disturbances }\end{array}$ \\
\hline & ITIC & TC-3 & CBEMA Curve and Application Note \\
\hline & SEMI & $\begin{array}{l}\text { SEMI } 42 \\
\text { SEMI } 47 \\
\text { SEMI } 49 \\
\text { SEMI } 50\end{array}$ & $\begin{array}{l}\text { Test Method for Semiconductor Process } \\
\text { Equipment Voltage Sag Susceptibility } \\
\text { Specification for Semiconductor Equipment } \\
\text { Voltage Sag Immunity } \\
\text { Guide for Semiconductor Factory Systems Voltage } \\
\text { Sag Immunity } \\
\text { Guide for Electric Utility Voltage Sag } \\
\text { Performance for Semiconductor Factories }\end{array}$ \\
\hline \multirow[t]{2}{*}{$\begin{array}{l}\text { Transients and } \\
\text { surges }\end{array}$} & \multirow[t]{2}{*}{ IEEE PES } & $\begin{array}{l}\text { PC62.41.1 } \\
\text { PC62.41.2 } \\
\text { PC62.45 }\end{array}$ & $\begin{array}{l}\text { Guide on the Surge Environment in Low-Voltage } \\
\text { AC power circuits } \\
\text { Recommended practice on surge characterization } \\
\text { in low-voltage ac power circuits } \\
\text { Recommended practice on surge testing for } \\
\text { equipment connected to low-voltage ac power } \\
\text { circuits }\end{array}$ \\
\hline & & PC62.xx & SPD Applications (3 projects) \\
\hline
\end{tabular}




\begin{tabular}{|l|l|l|l|}
\hline & IEC SC37A & $61643-1$ & $\begin{array}{l}\text { Performance requirements and testing methods for } \\
\text { low-voltage SPD } \\
\text { Selection and application principles for low } \\
\text { voltage power distribution systems }\end{array}$ \\
\cline { 2 - 4 } & IEC TC64 & $61643-12$ & $\begin{array}{l}\text { General basic information regarding surge } \\
\text { overvoltages and surge protection in low-voltage } \\
\text { ac power systems }\end{array}$ \\
\cline { 2 - 4 } & UIE & WG2 & $\begin{array}{l}\text { Guide to Quality of Electrical Supply for Industrial } \\
\text { Installations-Transients }\end{array}$ \\
\cline { 2 - 4 } & NEMA & VS-1 & $\begin{array}{l}\text { Performance requirements and testing methods for } \\
\text { low-voltage SPD (North American) }\end{array}$ \\
\cline { 2 - 4 } & UL & $\begin{array}{l}\text { Std 1449 } \\
\text { New }\end{array}$ & $\begin{array}{l}\text { Transient Voltage Surge Suppressor } \\
\text { Secondary surge protectors }\end{array}$ \\
\hline & IEEE & Withdrawn? & Glossary of Power Quality Terminology (P1433) \\
\cline { 2 - 4 } & CENELEC & EN 50 160 & $\begin{array}{l}\text { Voltage characteristics of electricity supplied by } \\
\text { public distribution systems }\end{array}$ \\
\cline { 2 - 4 } & NFPA & $\begin{array}{l}\text { NFPA70 } \\
\text { NFPA 789 }\end{array}$ & $\begin{array}{l}\text { National Electrical Code } \\
\text { Lightning Protection }\end{array}$ \\
\hline
\end{tabular}





\section{Appendix E Discussion of the Quality-Reliability-Availability Approach}

The electric power industry is beginning to look at reliability and quality of service as interrelated aspects of utility performance. Utility performance is no longer being considered independently of customer needs and responsibilities. The quality-reliability-availability (QRA) approach takes an integrated approach to power quality, service interruptions, end user requirements, and the service contract (written or implied) between the utility and its customers.

The Consortium for an Electric Infrastructure to Support a Digital Society (CEIDS) is proposing an alternative method for assessing power quality and reliability that uses the QRA approach. CEIDS is a joint initiative by EPRI and the Electricity Innovation Institute. The method includes definitions of power quality levels that add consideration of mean time between failure and mean time to repair, and assessment of QRA-enhancing options that maximize digital system uptime at optimal cost.

When quantifying the QRA of supply, it is important to define what constitutes a failure. Different loads respond in different ways to various voltage disturbances. It is appropriate to define several levels of quality because of this difference in response. The definition must go beyond traditional utility definitions of reliability (interruptions greater than 5 minutes) and include shorterduration events that cause customer disturbances.

In order of the most sensitive definition of a failure to the least sensitive, the levels that are initially proposed by CEIDS are these:

- Level 1: Any voltage sags below those established by the Information Technology Industry Council (ITIC) in the guideline known as the "ITIC curve." A failure is any voltage below 70\% of nominal for greater than 0.02 seconds or below $80 \%$ of nominal for greater than 0.5 seconds. The steady-state values on the ITIC curve (voltage below $90 \%$ of nominal for more than 10 seconds) are excluded. The overvoltage portion of the ITIC curve is also excluded.

- Level 2: A failure occurs if the voltage drops below $70 \%$ of nominal voltage for more than 0.2 seconds.

- Level 3: A failure is an interruption of at least 1 second.

- Level 4: A failure is an interruption of at least 5 minutes.

For the QRA approach, assessing the effects of an outage on a customer helps indicate what reliability indices and statistics are important. For a factory, even a momentary outage may shut down a production line and require 6 hours of inplant work to remove in-process material and restart the line. For this factory, it does not matter whether the utility has restored service in 5 minutes or in 3 hours. The factory wants fewer

For a factory, even a momentary outage may shut down a production line and require hours of work to restart. For this factory, it does not matter whether the utility restores services in 5 minutes or in 3 hours. The factory wants fewer interruptions, not necessarily shorter ones. interruptions, not necessarily shorter ones. QRA looks at which types of reliability or service quality are most important. A recloser will cause a momentary outage on an entire feeder, but in doing so it will prevent a fuse blowing on a feeder branch, which would result in an extended outage for all the customers on that branch. The factory used as an example would rather have the occasional extended outage (fuse) than the more frequent momentary outage (recloser). However, if the customer can install an uninterruptible power supply (UPS) or storage that allows it to ride through a momentary or short outage (1 to 2 minutes), then the recloser plus UPS may dramatically reduce outage-related costs. 
This is not a radical departure from the types of calculations and assessments that utilities, customers, and regulators have always done; but if the process is formalized, electricity consumers can know what level of reliability they should expect and all parties can compare the costs of improving reliability through system improvements (e.g., installing an alternate feed), versus improving reliability through customer-side measures (e.g., installing a UPS), versus costs incurred by the customers if reliability is not improved. The QRA approach begins to bridge the gap between generation, transmission, and distribution reliability assessment because it looks not only at the value of reliability but also at how best to improve the reliability (e.g., frequency versus duration of outages).

We anticipate that QRA may become a "best practice" for assessment of reliability and service quality. 


\section{Appendix F \\ Industry Initiatives to Define Power Quality: Discussion of the SEMI, CBEMA and ITIC Curves}

\section{Semiconductors Manufacturers' Institute}

One industry that has established its own specific level of power quality is the semiconductor manufacturing industry. The Semiconductors Manufacturers' Institute (SEMI) has developed a power quality need curve that simply shows the minimum voltage vs time that their equipment is expected to ride through an outage (Figure F.1). With this curve, semiconductor manufacturers can specify tools, adjustable speed drives, controllers, etc. that are designed to function during power quality events. The manufacturers can also specify the needed DER to ensure that they can ride through events worse than those covered by the need curve.

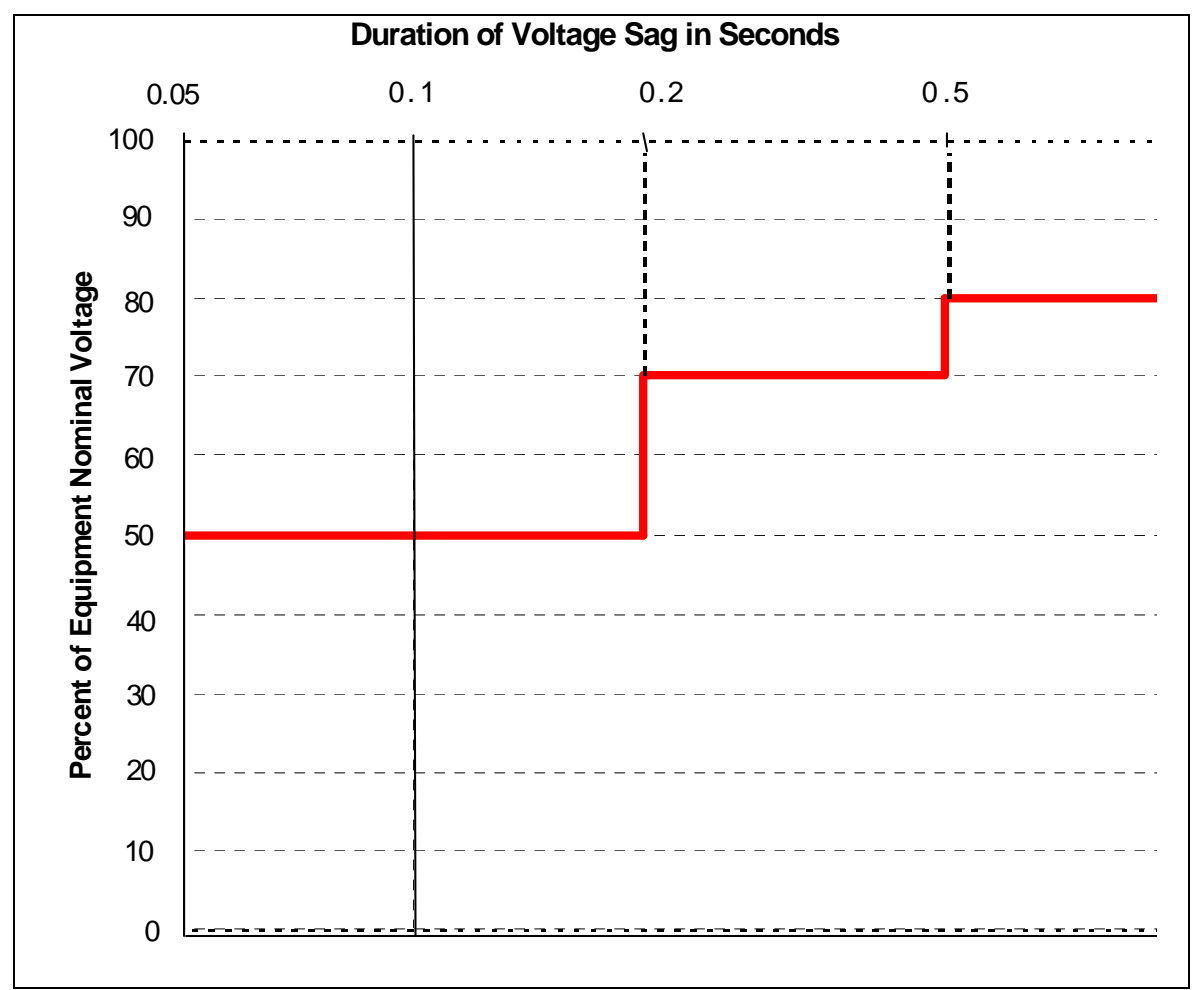

Figure F.1. Semiconductors Manufacturers' Institute provisional specification for voltage sag ride-through capability.

SEMI \#2844 is the ride-through limit curve for semiconductor tools

- The curve was developed from an analysis of 30 monitor years of disturbance data collected at major semiconductor sites.

- The proposed curve should result in less than one event per site per year.

- However, the curve requires $80 \%$ voltage at the longer durations, 1 second to 10 seconds.

- The curve is based on minimal use of energy storage devices; instead, it suggests the careful selection of devices such as tools, relays, and power supplies.

- The curve assumes direct connection to transmission; connection through a distribution feeder may result in sags and durations that would fail to meet the curve. 
- DER will enable the curve to be met in locations where direct connection to transmission is not possible.

The CBEMA curve is the defined power quality acceptability level defined by a group of computer manufacturers

- The CBEMA curve requires a return to $90 \%$ voltage after one minute.

- The CBEMA curve is more restrictive for the first 12 cycles.

- DER with energy storage and a power electronics interface could easily enable any manufacturing facility to meet either curve.

- The SEMI curve was created because so much SEMI equipment could not meet the CBEMA curve.

Figure F.2 is a histogram of sag and interruption rate magnitude. The solid line indicates the CBEMA acceptance limit, and the light blue dashed line indicates the SEMI 2844 acceptance limit. (This figure is from the EPRI Distribution Power Quality Study.) The numbers in the cells indicate the probability of a sag of that voltage and duration. These are based on 1-minute aggregations from 6/1/93 to 6/1/95. The SEMI curve is not as restrictive as the CBEMA limit.

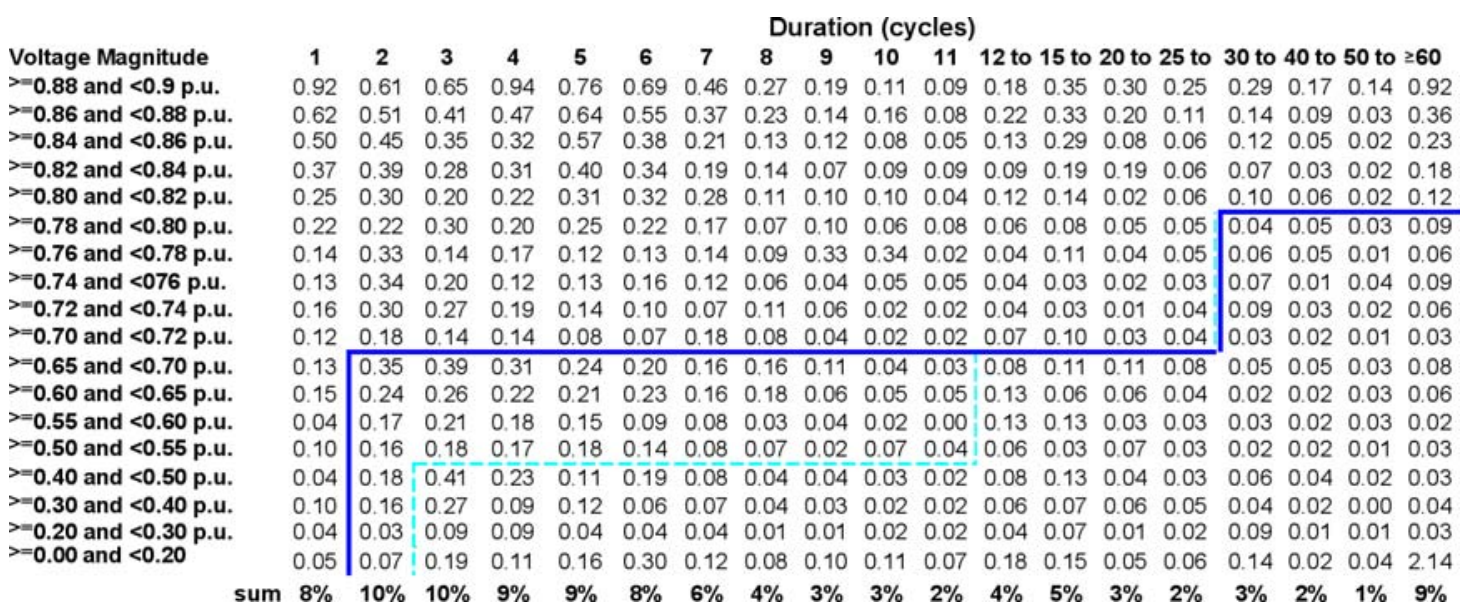

Figure F.2. A histogram of sag and interruption rate magnitude. The solid line indicates the CBEMA acceptance limit and the dashed line, the SEMI 2844 acceptance limit. The numbers in the cells indicate the probability of a sag of that voltage and duration, based on 1-minute aggregations from 6/1/93 to 6/1/95. Source: EPRI Distribution Power Quality Study.

\section{Information Technology Industry Council Curve}

ITIC, the successor organization to CBEMA, has developed the ITIC Curve, a recommended capability curve for single-phase data processing equipment operating at $120 \mathrm{~V}$. The ITIC Curve provides an easier graphical format to reproduce and requires improved ride-through capability for minor voltage sags (Figure F.3). However the curve is still general in nature and does not reflect typical performance for any particular type of equipment. 


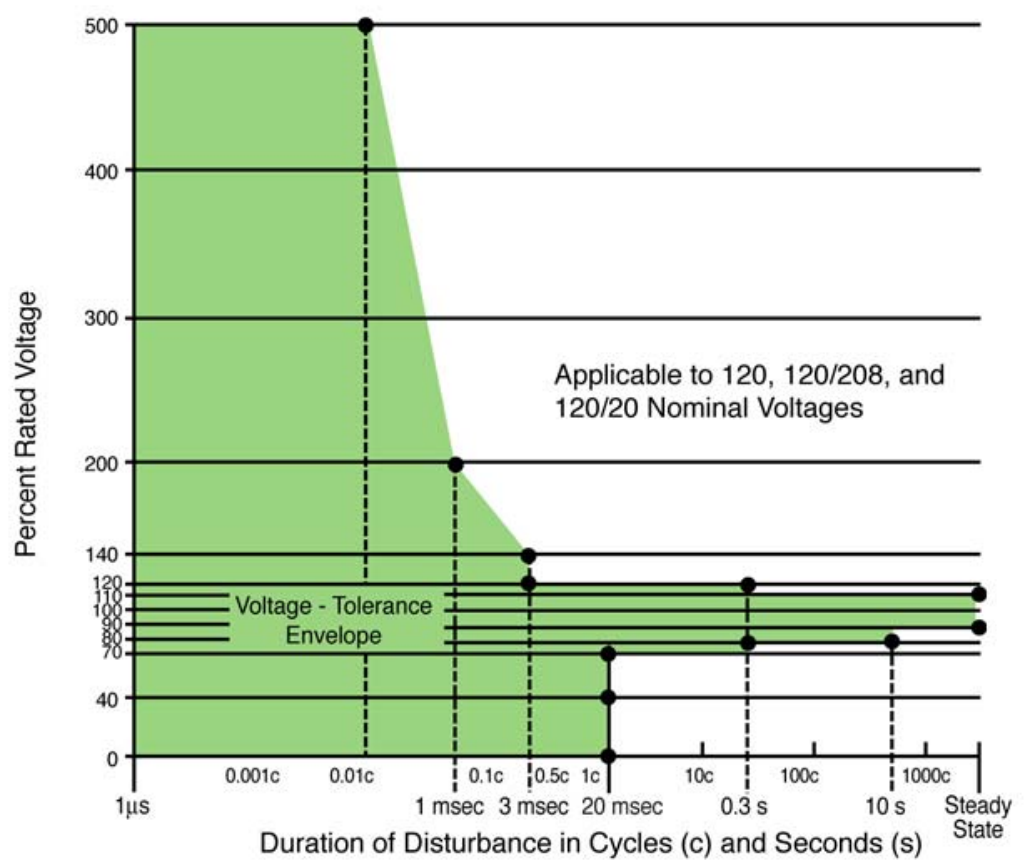

Figure F.3. ITIC curve defining voltage sag ride-through design goals for manufacturers of information technology equipment (applies to single-phase 120/240-V equipment). 
